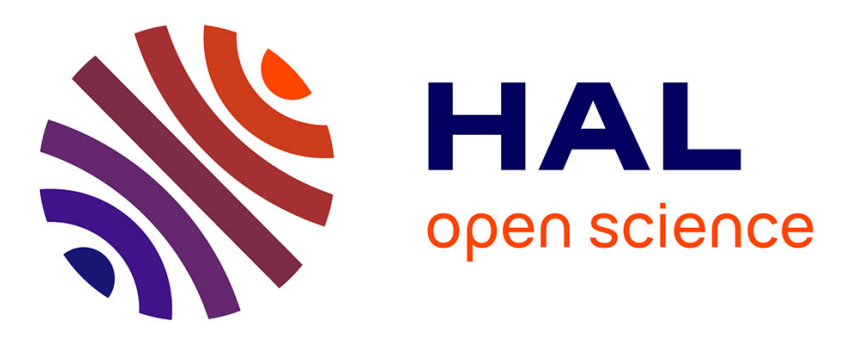

\title{
The Interaction between Surfactants and Montmorillonite and its Influence on the Properties of Organo-Montmorillonite in Oil-Based Drilling Fluids
} Guanzheng Zhuang, Zepeng Zhang, Shanmao Peng, Jiahua Gao, Francisco Pereira, Maguy Jaber

\section{To cite this version:}

Guanzheng Zhuang, Zepeng Zhang, Shanmao Peng, Jiahua Gao, Francisco Pereira, et al.. The Interaction between Surfactants and Montmorillonite and its Influence on the Properties of OrganoMontmorillonite in Oil-Based Drilling Fluids. Clays and Clay Minerals, 2019, 67 (3), pp.190-208. 10.1007/s42860-019-00017-0 . hal-02308616

\section{HAL Id: hal-02308616 https: / hal.sorbonne-universite.fr/hal-02308616}

Submitted on 8 Oct 2019

HAL is a multi-disciplinary open access archive for the deposit and dissemination of scientific research documents, whether they are published or not. The documents may come from teaching and research institutions in France or abroad, or from public or private research centers.
L'archive ouverte pluridisciplinaire HAL, est destinée au dépôt et à la diffusion de documents scientifiques de niveau recherche, publiés ou non, émanant des établissements d'enseignement et de recherche français ou étrangers, des laboratoires publics ou privés. 


\section{INTERACTION BETWEEN SURFACTANTS AND}

2 MONTMORILLONITE AND ITS INFLUENCE ON THE

3 PROPERTIES OF ORGANO-MONTMORILLONITE IN

4 OIL-BASED DRILLING FLUIDS

5 Guanzheng Zhuang ${ }^{1}$, Zepeng Zhang ${ }^{1, *}$, Shanmao Peng ${ }^{1}$, Jiahua Gao ${ }^{1}$, Francisco A.

$6 \quad$ R. Pereira ${ }^{2,3}$, and Maguy Jaber ${ }^{2, *}$.

$7 \quad{ }^{1}$ Beijing Key Laboratory of Materials Utilization of Nonmetallic Minerals and Solid

8 Wastes, National Laboratory of Mineral Materials, School of Materials Science and

9 Technology, China University of Geosciences, No. 29, Xueyuan Road, Haidian

10 District, Beijing 100083, PR China

$11{ }^{2}$ Sorbonne Université, Laboratoire d'Archéologie Moléculaire et Structurale (LAMS),

12 CNRS UMR8220, case courrier 225, UPMC 4 Pl. Jussieu, 75005 PARIS CEDEX 05,

13 France

$14{ }^{3}$ Chemistry Department, Science and Technology Center, Universidade Estadual da 15 Paraíba, Campina Grande, Paraíba, Brazil.

17 Corresponding Author:

18 Zepeng Zhang

19 Address: School of materials science and technology, China University of

20 Geosciences, Beijing, China.

21 Tel: $+86-010-8232-1845$

22 Fax: +86-10-8232-2974 
26 Maguy Jaber

27 Address: Sorbonne Université, Laboratoire d'Archéologie Moléculaire et Structurale 28 (LAMS), CNRS UMR8220, case courrier 225, UPMC 4 Pl. Jussieu, 75005 PARIS

29

30

31

32 33 
Abstract

47 The increasing demands of oil and gas and associated difficult drilling operations require oil-based drilling fluids that possess excellent rheological properties and thermal stability. The objective of the present work was to investigate the rheological properties and thermal stability of organo-montmorillonite (OMnt) modified with

51 different surfactants and different loading levels in oil-based drilling fluids, as revealed by the interaction between organic surfactants and montmorillonite. The influence of the structural arrangement of surfactants on the thermal stability of organo-montmorillonite (OMnt) in oil-based drilling fluids was also addressed. OMnt samples were prepared in aqueous solution using surfactants possessing either a single long alkyl chain and or two long alkyl chains. OMnt samples were characterized by

57 X-ray diffraction, high-resolution transmission electron microscopy, thermal analysis, and X-ray photoelectron spectroscopy. Organic surfactants interacted with montmorillonite by electrostatic attraction. The arrangements of organic surfactants depended on the number of long alkyl chains and geometrical shape of organic cations. In addition to the thermal stability of surfactants, intermolecular interaction also improved the thermal stability of OMnt/oil fluids. A tight paraffin-type bilayer arrangement contributed to the excellent rheological properties and thermal stability of OMnt/oil fluids. The deterioration of rheological properties of OMnt/oil fluids at temperatures up to $200^{\circ} \mathrm{C}$ was due mainly to the release of interlayer surfactants into the oil. 
Keywords: Arrangement, Oil-Based Muds, Organo-Clay, Rheological Properties, Thermal Behavior.

\section{INTRODUCTION}

Montmorillonite (Mnt) belongs to the general family of phyllosilicates. An ideal Mnt layer is composed of two continuous $\left[\mathrm{SiO}_{4}\right]$ tetrahedral sheets $(\mathrm{T})$ and an $\left[\mathrm{AlO}_{6}\right]$ octahedral sheet (O). Thus, the structure of Mnt is described as a TOT type (Bergaya et al., 2012). Due to isomorphic substitution, Mnt layers are often negatively charged.

A negatively charged layer arises from the substitution of $\mathrm{Mg}^{2+}$ and other smaller charge cations for $\mathrm{Al}^{3+}$ in octahedral sites (Brigatti et al., 2013; Jaber et al., 2014). Consequently, cations such as $\mathrm{Na}^{+}$and $\mathrm{Ca}^{2+}$ present in the interlayer space counterbalance the deficit of positive charges. Significantly, these cations are exchangeable (Lagaly, 1981) with organic cations such as quaternary ammonium salts and quaternary phosphonium salts.

The preparation of organo-montmorillonite (OMnt) with cationic surfactants (Paiva et al., 2008; He et al., 2010; Lagaly et al., 2013), non-ionic surfactants (Shen, 2001; Bertuoli et al., 2014; Guégan et al., 2015), anionic surfactants (Sarier et al., 2010; Zhang et al., 2010), and a mixture of different kinds of surfactants (Chen et al., 2008; Gunawan et al., 2010; Zhang et al., 2013; Wu et al., 2014) is reported commonly. OMnt prepared with cationic surfactants (often quaternary ammonium salts) are used widely in industrial and scientific applications. A substantial industry has been established for years to develop the utilization of OMnt in paint, adsorbents, greases, cosmetics, and nanocomposites, etc. (Jaber et al., 2002; Paiva et al., 2008; He 
et al., 2010; Lee and Tiwari, 2012).

An important use of OMnt is as a rheological additive in oil-based drilling fluids (Caenn and Chillingar, 1996; Caenn et al., 2011). Quaternary ammonium salts in which the alkyl chain has $12-22$ carbon atoms are usually used to prepare OMnt for oil-based drilling fluids (Dino and Thompson, 2002; Frantz, 2014); for example, cetyl trimethyl ammonium (Zhuang et al., 2016; Ratkievicius et al., 2017), octadecyl trimethyl ammonium chloride (Zhuang et al., 2017a), octadecyl benzyl dimethyl ammonium (Hermoso et al., 2014, 2017), and dimethyl dioctadecyl ammonium chloride (Hermoso et al., 2014, 2017). With the increasing demands of the oil and gas industry, drilling operations have been undertaken in many difficult wells, such as high-temperature, high-pressure, high-angle, and offshore wells. Oil-based drilling fluids are more popular due to their excellent lubricity, high rate of penetration, shale inhibition, wellbore stability, and good thermal stability (Caenn and Chillingar, 1996; Khodja et al., 2010).

Previous studies identified that the rheological properties of oil-based drilling fluids are affected by the concentration and nature of OMnt (Hermoso et al., 2014, 2015; Zhuang et al., 2016, 2017a). The lipophilicity of surfactants contributes to the compatibility between oil and OMnt. Furthermore, for the same surfactant, more surfactant usually results in a larger basal spacing and further improves the swelling ability or even exfoliation. Exfoliation of OMnt in oil improves the rheological properties (Zhuang et al. 2017a,c). The dissolution of organic surfactants into oil might be a crucial reason for the deterioration of rheological properties at high 
temperature. Such previous studies mostly reported the relationship between the structure and properties of OMnt and the properties of oil-based drilling fluids.

Some problems, however, are still unsettled: (i) how do organic surfactants remain stable on the exfoliated OMnt layers? (ii) what is the reason for the deterioration of rheological properties at high temperatures? and (iii) the influence of the arrangements of interlayer surfactants on the properties of oil-based drilling fluids is unresolved. The purpose of the present study was to try to resolve these problems, using two typical organic surfactants to modify Mnt, by determining the rheological properties and thermal stability of different OMnt samples in oil-based drilling fluids, thus revealing the interaction between organic surfactants and Mnt, and to measure the attendant structural changes in OMnt at the molecular scale.

\section{MATERIALS AND METHODS}

\section{Materials}

Mnt was obtained from the Kazuo Shuanglong Mining Co., Ltd, Liaoning Province, China. The mass percentage of montmorillonite included in the Mnt sample was calculated from X-ray diffraction (XRD) patterns (Chinese standard SY/T 5163-2010: Analysis method for clay minerals and ordinary non-clay minerals in sedimentary rocks by X-ray diffraction). This method was explained in a previous study (Zhuang et al., 2018). The calculation follows the formula: $X_{i}=\left[\frac{I_{i}}{K_{i}} /\left(\sum \frac{I_{i}}{K_{i}}\right)\right] \times$ $100 \%$, where $\mathrm{X}_{\mathrm{i}}$ is the mass percent of phase $\mathrm{i}$; $\mathrm{K}_{\mathrm{i}}$ is the intensity ratio of phase $\mathrm{i}$ to corundum with the mass ratio $\mathrm{i} /$ corundum $=1: 1$. For the current work, the $\mathrm{K}$ values of 
minerals are listed in Table 1. The XRD pattern of Mnt (Figure 1) indicated the presence of montmorillonite (88\%), quartz (7\%), calcite (2\%), albite (2\%), and pyrite (1\%) (Table 2). The cation exchange capacity (CEC) of the Mnt was $120 \mathrm{cmol}_{(+)} / \mathrm{kg}$. Cationic surfactant octadecyl trimethyl ammonium chloride (C18) and dimethyl dioctadecyl ammonium chloride (DC18) were purchased from Anhui Super Chemical Technology Co., Ltd, Hefei, Anhui, China. The ideal structures of these two organic cations (Figure 2) were optimized by ChemBio 3D using the molecular mechanics (MM2) minimization program (Bowen et al., 1987). The purity of the surfactants was 99\%. The base oil, No. 5 white oil, was obtained from the China National Petroleum Corporation.

\section{Preparation of OMnt}

OMnts were prepared in aqueous solution as reported previously (Zhuang et al., 2017a): $100 \mathrm{~g}$ of Mnt was added to $1 \mathrm{~L}$ of deionized water and stirred for $0.5 \mathrm{~h}$; surfactant was then added to the previous dispersion and the resulting dispersion stirred for $1 \mathrm{~h}$. Finally, after centrifugation, drying at $60^{\circ} \mathrm{C}$ for $24 \mathrm{~h}$, and milling and sieving with a 200-mesh sieve, OMnt was obtained. C18-modified OMnts were named C18-Mnt-1.0 and C18-Mnt-2.0, where 1.0 and 2.0 indicated that the amounts of $\mathrm{C} 18$ were equivalent to $1.0 \mathrm{CEC}$ or $2.0 \mathrm{CEC}$ of Mnt, respectively. Correspondingly,

OMnts prepared with DC18 (0.5 CEC and 1.0 CEC of Mnt) were marked as DC18-Mnt-0.5 and DC18-Mnt-1.0.

\section{Preparation of oil-based fluids}


$15630 \mathrm{~kg} / \mathrm{m}^{3}$ ) and blended for $20 \mathrm{~min}$ at $8000 \mathrm{rpm}$. A drilling fluid should be aged at 157 different temperatures to model the real drilling operation. The blended fluids were 158 placed in a rotary oven heated to $66^{\circ} \mathrm{C}, 150^{\circ} \mathrm{C}, 180^{\circ} \mathrm{C}$, and $200^{\circ} \mathrm{C}$ in which they were 159 aged for $16 \mathrm{~h}$. All the operations followed the standards of the American Petroleum 160 Institute (API), i.e. API SPEC 13A (Specification for Drilling Fluid Materials, 2010) 161 and API RP 13B-2 (Recommended practice for field testing oil-based drilling fluids, 162 2014). The oil-based fluids were named following the template of 163 OMnt/oil-temperature. For example, C18-Mnt-1.0/oil-66 was prepared by 164 C18-Mnt-1.0 and white oil aged at $66^{\circ} \mathrm{C}$.

165

166 167 168

\section{Characterization}

The XRD analysis was conducted using a Bruker D8 Advance X-ray powder diffractometer (Germany), using $\mathrm{Cu} \mathrm{K \alpha}$ radiation at $40 \mathrm{kV}$ and $40 \mathrm{~mA}$ and a scan speed of $0.05 \mathrm{~s}$ per step (step size of $0.02^{\circ}$ ). The XRD data points covered the range $1.5^{\circ}$ to $70^{\circ} 2 \theta$. The transmission electron microscope (TEM) analysis was conducted using Tecnai G2 F20 TEM equipment (Hillsboro, Oregon, USA) and operated under the voltage of $200 \mathrm{kV}$. Thermogravimetry (TG) analysis was tested on a NETZSCH STA 449 F3 type DTA-TG instrument (Selb, Bavaria, Germany) from room temperature to $900^{\circ} \mathrm{C}$ in air, with a heating rate of $10^{\circ} \mathrm{C} / \mathrm{min}$. The $\mathrm{X}$-ray photoelectron spectroscopy (XPS) analysis was carried out using a Thermo escalab 250Xi instrument (Waltham, Massachusetts, USA). Bombardment of the surface with X-rays

(monochromated $\mathrm{Al} \mathrm{K} \alpha$ radiation, $1486.6 \mathrm{eV}$ ) resulted in the emission of 
177 photoelectrons with element-specific binding energies (BE). Firstly, a survey scan in 178 the energy range of $1350-0 \mathrm{eV}$ was recorded at a resolution of $1 \mathrm{eV}$. Then, 179 high-resolution $\mathrm{O}$ 1s, $\mathrm{Si} 2 \mathrm{p}, \mathrm{Al} \mathrm{2p}, \mathrm{C}$ 1s, and $\mathrm{N} 1 \mathrm{~s}$ scans were obtained. The 180 rheological properties (apparent viscosity (AV), plastic viscosity (PV), and yield point 181 (YP)) of aged oil-based drilling fluids were determined at $20^{\circ} \mathrm{C}$, using a FANN 35A 182 viscometer (Qingdao HaiTongDa Special Purpose Instrument Co., Ltd., China). AV = $1831 / 2 \theta_{600}\left(\theta_{600}\right.$ is the dial reading at $600 \mathrm{rpm}$, corresponding to a shear rate of $\left.1021.8 \mathrm{~s}^{-1}\right)$. $184 \mathrm{PV}=\theta_{600}-\theta_{300}$ and $\mathrm{YP}=1 / 2\left(\theta_{300}-\mathrm{PV}\right)$. The dynamic rheological behavior of oil-based 185 fluids was measured using a Themo Scientific HAAKE Roto Visco 1 rotational 186 viscometer (USA). The programmed measurement regime was: the shear rate 187 increased linearly from $0 \mathrm{~s}^{-1}$ to $100 \mathrm{~s}^{-1}$ in $5 \mathrm{~min}$ (up step), and then decreased linearly 188 from $100 \mathrm{~s}^{-1}$ to $0 \mathrm{~s}^{-1}$ in $5 \mathrm{~min}$ (down step).

RESULTS AND DISCUSSION

XRD of OMnt powders

The basal reflection of Mnt occurred at $7.05^{\circ} 2 \theta$, corresponding to $d_{001}=1.25 \mathrm{~nm}$

(Figure 1). After organic modification, the basal spacing of OMnt increased (Figure 3), giving $d_{001}$ values for C18-Mnt-1.0, C18-Mnt-2.0, DC18-Mnt-0.5, and DC18-Mnt-1.0 of $2.12 \mathrm{~nm}, 4.06 \mathrm{~nm}, 3.51 \mathrm{~nm}$, and $3.68 \mathrm{~nm}$, respectively. The $d_{001}$ of C18-Mnt-2.0 is almost double the $d_{001}$ of C18-Mnt-1.0. In the case of DC18-modified OMnt, however, the $d_{001}$ of DC18-Mnt-1.0 increased by $~ 5 \%$ over DC18-Mnt-0.5. This phenomenon indicated that C18 and DC18 occupied very different structural arrangements in OMnt. 
The (002) and (003) reflections emerged in the XRD patterns of C18-Mnt-2.0, DC18-Mnt-0.5, and DC18-Mnt-1.0, whereas no peaks can be referred to (002) and (003) reflections in the XRD pattern of C18-Mnt-1.0. The basal reflection intensity showed the sequence of DC18-Mnt-1.0 > C18-Mnt-2.0 > DC18-Mnt-0.5> C18-Mnt-1.0. Thus, the order of the degree of layer stacking (along the $c$ axis) follows DC18-Mnt-1.0 > C18-Mnt-2.0 > DC18-Mnt-0.5 > C18-Mnt-1.0. DC18 likely was arranged in a more ordered manner in the interlayer space than C18.

\section{TEM analysis}

High-resolution TEM images (Figure 4) gave information about the basal spacing and the thickness of platelets. The TEM images of raw Mnt showed tightly stacked aluminosilicate layers. The thickness of the platelets of raw Mnt was $>50 \mathrm{~nm}$ and the lamellae contained >50 layers. The lamellae of OMnt were thicker than those of raw Mnt and contained fewer layers. For both C18- and DC18-modified OMnt, more surfactant led to thicker lamellae. The thickness of C18-Mnt-1.0 lamellae was a little larger than that of DC18-Mnt-0.5 lamellae, and the thicknesses of C18-Mnt-2.0 and DC18-Mnt-1.0 lamellae were similar. This fact indicates that 1.0 CEC DC18 and 2.0 CEC C18 resulted in similar effects on the thickness of OMnt lamellae.

The TEM images also revealed the basal spacing directly. The layers in C18-Mnt-1.0 were not arranged neatly and the basal spacing ranged from 1.44 to $1.79 \mathrm{~nm}$. Ordered stacking of layers was observed in the TEM images of C18-Mnt-2.0, DC18-Mnt-0.5, and DC18-Mnt-1.0. DC18-modified OMnt samples were more likely 
to exhibit an ordered arrangement of layers. More surfactant also led to ordered layer stacking. The basal spacing derived from the TEM images, however, was smaller than the results derived from XRD (Table 3). This phenomenon might be caused by the radiation damage from the high voltage $(200 \mathrm{kV})$. The lattices of clay minerals are easily damaged by high voltage in high-resolution TEM (Kogure, 2013). Surfactants would degrade under high voltage, resulting in the decrease of basal spacing. $\Delta d_{001}$ indicated the change of arrangement of the interlayer surfactants. C18-Mnt-2.0 exhibited the largest $\Delta d_{001}$ value, demonstrating the dramatic re-organization of interlayer surfactants under high voltage. The similar $\Delta d_{001}$ values of DC18-Mnt-0.5 and DC18-Mnt-1.0 suggested similar arrangements of interlayer surfactants in these two OMnt samples.

\section{Thermal analysis}

Mnt showed two steps of mass loss (Figure 5). The first step $\left(<150^{\circ} \mathrm{C}\right)$, corresponding to a mass loss of $6.8 \%$, was attributed to the loss of the water molecules on the surface and in the interlayer space of Mnt (He et al., 2005; Zhuang et al., 2015). The second mass loss step $\left(500-745^{\circ} \mathrm{C}\right.$, mass loss of $\left.6.3 \%\right)$ represented the dehydration of hydroxyl groups coordinated by the structural cations in tetrahedral and octahedral sites (Greene-Kelly, 1957; Hedley et al., 2007). The organic surfactants completely decompose above $500^{\circ} \mathrm{C}$. The onset temperatures $\left(T_{\text {onset }}\right)$ corresponding to the thermal decomposition of C18 and DC18 were $202^{\circ} \mathrm{C}$ and $145^{\circ} \mathrm{C}$, respectively, indicating that $\mathrm{C} 18$ is more thermally stable than DC18. 

surfactants $\left(150^{\circ} \mathrm{C}\right.$ to $\left.430^{\circ} \mathrm{C}\right)$, continuous oxidation of organic surfactants $\left(430^{\circ} \mathrm{C}\right.$ to $\left.650^{\circ} \mathrm{C}\right)$, and dehydration of hydroxyl groups $\left(650^{\circ} \mathrm{C}\right.$ to $\left.800^{\circ} \mathrm{C}\right)$ can be observed in the

TG and DTG curves of OMnt. The percentage water loss from C18-Mnt-1.0,

247 C18-Mnt-2.0, DC18-Mnt-0.5, and DC18-Mnt-1.0 was 2.2\%, 1.8\%, 0.8\%, and 0.0\%, respectively. OMnt samples contained less water than Mnt. In addition, C18-modified

249 OMnt samples contained more adsorbed water than DC18-modified OMnt samples.

250 The main factors affecting the interlayer hydration of montmorillonite include:

251 (i) hydration energy of the interlayer cations, (ii) polarization of the water molecules by interlayer cations, (iii) variation of the electrostatic surface potentials because of 253 differences in layer charge locations, (iv) activity of water, and (v) size and morphology of the clay particles (Brigatti et al., 2013). Although C18 and DC18 255 cations had the same positive charges with $\mathrm{Na}^{+}$cations, the organic cations showed a 256 larger size and lower polarity due to the alkyl chains. In addition, the hydrophobicity 257 of organic cations could prevent the adsorption of water. DC18 cations exhibited a 258 larger size and better hydrophobicity than C18 cations, resulting in less interlayer 259 water in the DC18-modified OMnt.

The $T_{\text {onset }}$ corresponding to the thermal decomposition of organic surfactants in 261 OMnt samples revealed the thermal stability of the samples. The $T_{\text {onset }}$ values of C18, 262 C18-Mnt-1.0, and C18-Mnt-2.0 were $202^{\circ} \mathrm{C}, 185^{\circ} \mathrm{C}$, and $175^{\circ} \mathrm{C}$, respectively. The $263 T_{\text {onset }}$ values of DC18, DC18-Mnt-0.5, and DC18-Mnt-1.0 were $145^{\circ} \mathrm{C}, 180^{\circ} \mathrm{C}$, and $264159^{\circ} \mathrm{C}$, respectively. C18-modified OMnt, therefore, showed better thermal stability 

that of $\mathrm{C} 18$ because organic surfactants not only intercalated into the interlayer space,

267 but also occupied the outer surface (He et al., 2005; Hedley et al., 2007; Zhu et al., 268 2011). The interlayer surfactants were protected by the Mnt layers. However, the 269 surfactants exposed on the external surface were more susceptible to thermal degradation without the protection of the Mnt interlayers. Evidently, surfactants were 271 mostly intercalated in the interlayer space when the surfactant loading level was $<1.0$ 272 CEC of Mnt. When more surfactant was used, more should have adsorbed on the 273 external surface, resulting in the decrease of $T_{\text {onset }}$ (Zhuang et al., 2016). For 274 DC18-modified OMnt, most of the surfactant was intercalated into the interlayer 275 space due to the smaller amount of surfactant ( $\leq 1.0 \mathrm{CEC})$. Accordingly, DC18-Mnt 276 exhibited better thermal stability than the pure surfactant.

XPS analysis

The XPS survey scans of Mnt (Figure 6) showed the presence of $\mathrm{O}, \mathrm{Si}, \mathrm{Al}, \mathrm{Mg}$, $280 \mathrm{Fe}, \mathrm{Na}$, and $\mathrm{C}$ in Mnt. The presence of $\mathrm{C}$ in Mnt was assigned to calcite. After 281 surfactant modification, the signals of $\mathrm{N}$ and $\mathrm{Cl}$ emerged in the spectra of $\mathrm{OMnt}$ samples. In addition, the intensity of the $\mathrm{C} 1 \mathrm{~s}$ signal in OMnt was much greater than 283 that in Mnt, demonstrating the adsorption and intercalation of organic surfactants. The 284 signals of $\mathrm{Cl} 2 \mathrm{~s}$ and $\mathrm{Cl} 2 \mathrm{p}$ in $\mathrm{C} 18-\mathrm{Mnt}-2.0$ were more intense than those in other 285 OMnt samples. This phenomenon indicated that more $\mathrm{Cl}^{-}$ions are included in 286 C18-Mnt-2.0, because the excess surfactant (more than 1.0 CEC of Mnt) cannot 
intercalate into the interlayer space via cation exchange but remains neutral as an ion pair with $\mathrm{Cl}^{-}$(He et al., 2007).

Oxygen is the element most exposed on the surface of Mnt and TOT layers. Interaction between Mnt and surfactants should, therefore, first affect the binding energy of $\mathrm{O}$. The binding energy of $\mathrm{O} 1 \mathrm{~s}$ in Mnt was $532.5 \mathrm{eV}$ (Figure 7), representing oxygen in $\mathrm{Si}-\mathrm{O}(\mathrm{H})$ and $\mathrm{Al}(\mathrm{Mg}, \mathrm{Fe})-\mathrm{O}(\mathrm{H})$ groups. Compared with Mnt, the binding energy of $\mathrm{O} 1 \mathrm{~s}$ in OMnt samples was smaller, indicating greater electron density around $\mathrm{O}$ atoms in OMnt. The high-resolution XPS scans of Si 2p (Figure 8) and Al 2p (Figure 9) also showed a decrease in binding energy, suggesting that the $\left[\mathrm{SiO}_{4}\right]$ tetrahedra and $\left[\mathrm{Al}(\mathrm{Mg}, \mathrm{Fe}) \mathrm{O}_{6}\right]$ octahedra, as a whole, exhibited higher electron densities after organic modification.

The C 1s spectra (Figure 10) of surfactants can be distinguished as two parts: C-C groups corresponding to a binding energy of $284.8 \mathrm{eV}$ and $\mathrm{C}-\mathrm{N}$ groups corresponding to $285.9 \mathrm{eV}$ (C18) and $286.0 \mathrm{eV}$ (DC18) (He et al., 2007; Schampera et al., 2015). The binding energy of $\mathrm{C} 1 \mathrm{~s}$ involving $\mathrm{C}-\mathrm{C}$ groups maintained a constant value of $284.8 \mathrm{eV}$ after organic modification, indicating no interaction involving the long alkyl chains. The binding energy of C 1s spectra involving C-N groups, however, shifted to larger values, demonstrating the decline of electron density around $\mathrm{C}$ atoms connecting with N. From the high-resolution XPS spectra of N 1s (Figure 11) in organic surfactants, the binding energy of $\mathrm{N}$ 1s was $402.1 \mathrm{eV}$. However, the binding energy of $\mathrm{N} 1 \mathrm{~s}$ in OMnt increased slightly, demonstrating a decrease of electron density around $\mathrm{N}$. The decrease of binding energies of $\mathrm{N} 1 \mathrm{~s}$ and $\mathrm{C} 1 \mathrm{~s}$ in the $\mathrm{C}-\mathrm{N}$ 
groups proved that the reduction of electron density occurs only in the polar heads of surfactants, without the long alkyl chains.

From the high-resolution XPS spectra, the interaction between Mnt and organic surfactants occurred between the TOT layers of Mnt and polar heads of surfactants. TOT layers were electron acceptors and the polar heads of organic surfactants were electron donors. The shift of the binding energy $(\triangle \mathrm{BE})($ Table 4$)$ value of $\mathrm{O} 1 \mathrm{~s}$ was in the range of -1.2 to $-1.0 \mathrm{eV}$. The $\Delta \mathrm{BE}$ value of $\mathrm{C} 1 \mathrm{~s}(\mathrm{C}-\mathrm{N})$ was between 0.3 and $0.5 \mathrm{eV}$ and that of $\mathrm{N} 1 \mathrm{~s}$ was in the range $0.1-0.3 \mathrm{eV}$. Two conclusions can be drawn 317 from the XPS results: (i) no new signals emerged in the XPS spectra, except for small 318 changes in binding energy; (ii) compared with Mnt and surfactants, the binding 319 energy of Mnt elements (O 1s, Si 2p and Al 2p) in OMnt decreased while the 320 surfactant elements ( $\mathrm{C}$ 1s and $\mathrm{N} \mathrm{1s}$ ) in OMnt increased. Considering the negatively 321 charged Mnt layers and organic cations, the XPS results demonstrate electrostatic attraction between the TOT layers and the polar heads of surfactants, without

323 chemical bonds. The binding energy of O 1s in C18-Mnt-2.0 showed the smallest shift 324 because extra surfactants intercalate into the interlayer space in the form of ion pairs $325\left(\mathrm{Cl}^{-}\right.$anions and $\mathrm{C} 18$ cations). DC18-modified OMnt samples showed smaller $\Delta \mathrm{BE}$ 326 values than C18-modified OMnt samples, due to the conjugated effect of two long 327 alkyl chains.

Arrangements and interactions of interlayer surfactants 
only by the quantity of electricity. Thus, electrostatic attraction is irrelevant to the molecular size or conformation. Previous reports revealed that OMnt modified with

333 different surfactants exhibited different properties and thermal stability. Hence, the 334 interaction between organic surfactants should be considered. C18 cations, having a 335 single long alkyl chain, can be considered as having a 'linear shape' and DC18 cations 336 can be regarded as being 'V-shaped' due to its two long alkyl chains (Figure 1). 337 Interlayer surfactants arrange themselves as lateral-monolayer, lateral-bilayer, 338 pseudo-trimolecular layer, paraffin-type monolayer. or paraffin-type bilayer (Vaia et 339 al., 1994; Lagaly et al., 2013). The arrangements of interlayer surfactants are 340 influenced by the loading level, conformation of surfactants, the length of the alkyl 341 chain, and even the charge of Mnt. Short-chain alkylammonium cations are arranged 342 in monolayers and longer chain alkylammonium ions in bilayers with the alkyl chain 343 axes parallel to the silicate layers (Lagaly et al., 2013); a pseudo-trimolecular 344 arrangement is often observed with highly charged smectites and/or long surfactant 345 cations. The periodicity along the $c$ axis of Mnt (without cations and water) is $3460.96 \mathrm{~nm}$ (Brigatti et al., 2013). Considering the size of the C18 cation (Figure 1), 347 C18-modified OMnts ideally exhibit a basal spacing of $1.33 \mathrm{~nm}$ with a monolayer 348 arrangement, $1.73 \mathrm{~nm}$ with a bilayer arrangement, and $2.19 \mathrm{~nm}$ with a 349 pseudo-trimolecular arrangement. Lagaly et al. (2013) concluded that the monolayer 350 arrangement had a basal spacing of $1.4 \mathrm{~nm}$, the bilayer $1.8 \mathrm{~nm}$, and the 351 pseudo-trimolecular arrangement $2.2 \mathrm{~nm}$. Thus, the basal spacing $(2.12 \mathrm{~nm})$ of 352 C18-Mnt-1.0 suggests that C18 molecules were arranged as a pseudo-trimolecular 
layer (Figure 12). The positive heads of $\mathrm{C} 18$ were attached on the silicate layers, whereas the alkyl chains assumed a trimolecular arrangement by the formation of kinks. The pseudo-trimolecular arrangement of $\mathrm{C} 18$ cannot result in ordered arrangements of $\mathrm{C} 18$ cations in the interlayer space. In addition, the octadecyl chains could kink by formation of gauche bonds at different C atoms (Lagaly, 1976). Hence, the arrangement of $\mathrm{C} 18$ molecules was not sufficiently homogeneous to form very ordered stacks of layers. Only the low-intensity (001) reflection, therefore, emerged in the XRD patterns of C18-Mnt-1.0; the TEM image also testified to the non-uniform basal spacing. With the increase of loading level or alkyl chain length, organic cations tended to be arranged as a paraffin-type in a tilted to vertical arrangement (Lagaly, 1986). Based on the basal spacing of $4.06 \mathrm{~nm}, \mathrm{C} 18-\mathrm{Mnt}-2.0 \mathrm{~nm}$ is proposed to be arranged as a tilted paraffin-type bilayer (Figure 12). The tilting angle, $\theta$, is correlated positively with the amount of intercalated organic surfactants. In the case of C18-Mnt-2.0, $\theta$ is $52^{\circ}$. 1.0 CEC organic cations were assumed to exchange all the inorganic cations and occupy all the negative sites. The extra 1.0 CEC surfactants cannot intercalate into the interlayers completely because all of the exchangeable sites had been occupied. They should be adsorbed in the form of ion pairs (with anions). More surfactant molecules resulted in a tight arrangement, which made every single surfactant molecule hard to move. Consequently, C18-Mnt-2.0 showed a more ordered structure and displayed (002) and (003) reflections. 
DC18 has two long octadecyl chains. Considering the size of the DC18 and the basal spacing of OMnt, DC18 molecules in the interlayer space of DC18-Mnt-0.5 and DC18-Mnt-1.0 must arrange themselves in the form of a paraffin-type bilayer (Figure 12). The angle between the two octadecyl chains varied with the loading level. The most stable conformation of DC18 corresponded to an angle of $\sim 118.9^{\circ}$. This angle, however, must gradually reduce in order to accommodate more DC18 cations, i.e. $\alpha>\varphi>\gamma$. Finally, an almost parallel orientation of the chains was attained by formation of gauche bonds near the ammonium group. The conformation of DC18 cations allowed a denser packing of these surfactants in mono-and bimolecular films (Favre and Lagaly, 1991). This intensive arrangement with a strong interaction between DC18 cations bound individual cations together.

\section{Rheological properties of OMnt in oil}

Drilling fluids are often evaluated using the Bingham plastic flow model and are often required to work in high-temperature conditions with low viscosity. Generally, $\mathrm{AV}$ is used as the effective viscosity to evaluate the viscosity of drilling fluids. PV is not expected to be too high, because extremely high PV would make starting to drill difficult. The rheological properties of OMnt/oil drilling fluids (AV, PV, and YP) vary with different temperatures of ageing (Table 5). A commercial OMnt (DG-Mnt), as used by Mud Service Company, Bohai Drilling Engineering Co. Ltd, was used as a reference. DG-Mnt/oil, C18-Mnt-1.0/oil, and DC18-Mnt-0.5/oil fluids all showed quite low viscosities and yield points. Their yield points were zero or very close to 
zero, indicating these OMnt/oil fluids possessed no gel strength. Although the values of $\mathrm{AV}, \mathrm{PV}$, and YP were stable, the thermal stabilities of DG-Mnt/oil, C18-Mnt-1.0/oil, and DC18-Mnt-0.5/oil fluids were meaningless because of their poor rheological properties. Compared to the rheological properties of DG-Mnt/oil, C18-Mnt-1.0/oil, and DC18-Mnt-0.5/oil fluids, the rheological properties of C18-Mnt-2.0/oil and DC18-Mnt-1.0/oil fluids were dramatically increased. This result demonstrates that more surfactants lead to better rheological properties. C18-Mnt-2.0 showed bigger $d_{001}$ than DC18-Mnt-1.0; however, DC18-Mnt-1.0/oil fluids presented better rheological properties than C18-Mnt-2.0/oil fluids. This phenomenon testifies that a bigger basal spacing does not necessarily result in better rheological properties. The rheological properties of OMnt in oil-based drilling fluids should not be influenced only by surfactant loading level and basal spacing, but also by the arrangements of interlayer surfactants. The AV and YP of both C18-Mnt-2.0/oil and DC18-Mnt-1.0/oil fluids firstly increased and finally decreased with rising temperature. For example, the viscosity of C18-Mnt-2.0/oil fluid increased from $16.5 \mathrm{mPa}$ at $66^{\circ} \mathrm{C}$ to $31.0 \mathrm{mPa} \cdot \mathrm{s}$ at $150^{\circ} \mathrm{C}$, then decreased to $26.5 \mathrm{mPa}$ s at $180^{\circ} \mathrm{C}$ and $24.0 \mathrm{mPa} \mathrm{s}$ at $200^{\circ} \mathrm{C}$. The $\mathrm{AV}$ of DC18-Mnt-1.0/oil fluid and the YP of C18-Mnt-2.0/oil and DC18-Mnt-1.0/oil fluids are affected similarly. Viscosity and gel strength improved with increasing temperature because higher temperatures promote the swelling and even exfoliation of OMnt in oil (Zhuang et al., 2017a, 2017c). Temperature increase above $180^{\circ} \mathrm{C}$, however, was harmful for rheological properties. Focusing on the rheological properties of OMnt/oil fluids aged at 150 to $200^{\circ} \mathrm{C}$, DC18-Mnt-1.0/oil fluid was more 
stable than C18-Mnt-2.0/oil fluid. The AV of DC18-Mnt-1.0/oil fluid decreased from 47.0 $\mathrm{mPa}$ s to $40.0 \mathrm{mPa}$ s and the YP decreased from 18.0 Pa to 15.0 Pa. But the AV of C18-Mnt-2.0/oil fluid decreased from $31.0 \mathrm{mPas}$ to $24.0 \mathrm{mPa} \mathrm{s}$ and the YP decreased from 15.0 Pa to 3.0 Pa.

The dynamic rheological curves of OMnt/oil fluids (Figure 13) revealed rheological behavior and thixotropy. The DG-Mnt/oil, C18-Mnt-1.0/oil, and DC18-Mnt-0.5/oil fluids showed non-linear curves and presented low shear stress, in agreement with the results in Table 5. The rheological curves of DG-Mnt/oil, C18-Mnt-1.0/oil, and DC18-Mnt-0.5/oil can be divided into two parts: (i) the Bingham plastic model (a line which does not cross the zero point) in the range of 20-100 s ${ }^{-1}$; (ii) deviation from the Bingham plastic model to the zero point. DC18-Mnt-1.0/oil fluid exhibited greater shear stress than C18-Mnt-2.0/oil fluid. The shear stress of C18-Mnt-2.0/oil decreased dramatically from $150^{\circ} \mathrm{C}$ to $200^{\circ} \mathrm{C}$. However, the rheological curve of DC18-Mnt-1.0/oil aged at $180^{\circ} \mathrm{C}$ nearly coincided with that of DC18-Mnt-1.0/oil aged at $150^{\circ} \mathrm{C}$. When the temperature increased to $200^{\circ} \mathrm{C}$, the shear stress decreased a little.

Thixotropy is another important rheological property. It is a reversible isothermal transformation of a colloidal sol to a gel. In drilling practice, low resistance (low viscosity) is expected for the bit to ensure a rapid drilling rate, while high viscosity is needed for carrying cuttings. Excellent thixotropy is, thus, a necessary property of an oil-based drilling fluid. The areas of thixotropic loops (Figure 13) were applied to evaluate thixotropy of OMnt/oil fluids. The areas were calculated by integration 
DC18-Mnt-0.5/oil fluids showed very small areas, indicating nearly no thixotropy of

443 these fluids. The area of $\mathrm{C} 18-\mathrm{Mnt}-2.0 / \mathrm{oil}$ aged at $66^{\circ} \mathrm{C}$ is $2.61 \mathrm{~Pa} \mathrm{~s}^{-1}$. It increased to 193.43 $\mathrm{Pa} \mathrm{s}^{-1}$ at $150^{\circ} \mathrm{C}$, then decreased to $27.50 \mathrm{~Pa} \mathrm{~s}^{-1}$ at $200^{\circ} \mathrm{C}$, declining by $86 \%$ 445 from the area at $150^{\circ} \mathrm{C}$. The area of DC18-Mnt-1.0/oil aged at $66^{\circ} \mathrm{C}$ was $26.21 \mathrm{~Pa} \mathrm{~s}^{-1}$ 446 and then increased to $424.68 \mathrm{~Pa} \mathrm{~s}^{-1}$, indicating that high temperature below $150^{\circ} \mathrm{C}$ 447 promotes thixotropy. With the temperature rising to $200^{\circ} \mathrm{C}$, the area decreased to $448324.85 \mathrm{~Pa} \mathrm{~s}^{-1}$ at $200^{\circ} \mathrm{C}$, down by $19 \%$ from that at $150^{\circ} \mathrm{C}$. This result demonstrated 449 that the thixotropy of DC18-Mnt-1.0/oil fluid was more stable than that of 450 C18-Mnt-2.0/oil fluid. of DC18-Mnt-1.0/oil > C18-Mnt-2.0/oil > DC18-Mnt-0.5/oil C18-Mnt-2.0/oil. Two 453 possible reasons for decrease of rheological properties at high temperatures can be 454 proposed: (i) thermal decomposition of surfactants and (ii) dissolution of interlayer 455 surfactants into oil. Based on the thermal analysis results, DC18-Mnt-1.0 started to 456 decompose below $180^{\circ} \mathrm{C}$ (in air). But DC18-Mnt-1.0/oil fluid showed very stable 457 rheological properties at $200^{\circ} \mathrm{C}$, indicating the thermal stability of OMnt in oil was 458 improved due to the lack of oxygen. Thus, the decline of other OMnt/oil fluids below $459200^{\circ} \mathrm{C}$ was not caused by thermal decomposition. The only possibility is the 460 dissolution of interlayer surfactants into oil at high temperature. The HLB values of 461 C18 and DC18 are 14.9 and 6.8. DC18 showed more lipophilicity than C18. 
463

464

465

466

467

468

469

470

471

472

473

474

475

476

477

478

479

480

481

482

483

484

indicating that the paraffin-type bilayer of DC18 in OMnt can resist high temperatures better than the paraffin-type bilayer of C18.

XRD of OMnt/oil gels

To reveal the relationship between the thermal stability of OMnt/oil fluids and the arrangement of surfactants in the interlayer space of OMnt, the structure of OMnt in oil must be known. The structural change of OMnt in oil can be determined by XRD of OMnt/oil gel (Figure 14). All the samples showed a wide and low-intensity reflection at $17^{\circ} 2 \theta$, which is assigned to the oil (Zhuang et al., 2017b). Two reflections, corresponding to $d$ values of $2.05-2.06 \mathrm{~nm}$ and $1.38-1.43 \mathrm{~nm}$, emerged in the $\mathrm{C} 18-\mathrm{Mnt}-1.0 /$ oil aged at $66^{\circ} \mathrm{C}, 150^{\circ} \mathrm{C}$, and $180^{\circ} \mathrm{C}$. The $d$ values of these two reflections were smaller than the basal spacing of C18-Mnt-1.0 $(2.12 \mathrm{~nm})$, suggesting that the $d_{001}$ of C18-Mnt-1.0 in oil was reduced. Thermal analysis results proved that C18-Mnt-1.0 was stable up to $180^{\circ} \mathrm{C}$. Therefore, the decrease of basal spacing must be due to the surfactants dissolving in oil. These two reflections cannot be attributed to (001) and (002) reflections, because the $d$ value of the second reflection is not half that of the first. The two reflections, therefore, represented different basal spacings, indicating that the interlayer surfactants dissolved into oil gradually. The surfactants on the surfaces and edges dissolved first, then the internal surfactants dissolved, resulting in two reflections. Finally, aged at $200^{\circ} \mathrm{C}$, most of the surfactants in the interlayer space were lost, leading to one reflection with $d$ value of $1.36 \mathrm{~nm}$. This phenomenon also demonstrated that high temperature promoted the dissolution of 
485 486

487 488 489 490 491

interlayer surfactants, possibly because high temperature facilitated the thermal motion of oil molecules and surfactant molecules. A similar phenomenon happened to DC18-Mnt-0.5/oil fluid. The shrinkage of basal spacings of C18-Mnt-1.0 and DC18-Mnt-0.5 in oil demonstrated that loose arrangements resulted in the easy loss of interlayer surfactants. The basal spacing of C18-Mnt-2.0 increased gradually as the temperature increased to $180^{\circ} \mathrm{C}$. The basal spacing of C18-Mnt-2.0 in oil reached a maximum value of $4.33 \mathrm{~nm}$ when aged at $150^{\circ} \mathrm{C}$, corresponding to the best rheological properties of C18-Mnt-2.0/oil fluid. Aged at $200^{\circ} \mathrm{C}$, the basal spacing of C18-Mnt-2.0 in oil declined to $1.39 \mathrm{~nm}$. Although C18 cations and molecules are arranged tightly, the interlayer $\mathrm{C} 18$ was still lost at high temperature because no strong interaction force exists among the surfactants.

DC18-Mnt-1.0/oil-66 showed a similar reflection to DC18-Mnt-1.0 powder, indicating that no swelling happened, and no surfactants were lost. Because of the tight arrangement of DC18 in OMnt, no extra space was available to accept oil molecules. Below $15^{\circ} 2 \theta$, no reflection is observed in the XRD patterns of DC18-Mnt/oil gels aged at high temperatures, while the (100) reflection remained. Thus, DC18-Mnt-1.0 was exfoliated in oil at high temperatures because of thermal motion and interaction among surfactants. Surfactants in the interlayer space were protected by silicate layers, resulting in stabilization. DC18 cations could still remain stably on the surface of exfoliated layers because the strong interaction between DC18 cations fixed them tightly on the nanolayers. Hence, tight arrangement and strong interaction are necessary for the stability of OMnt in oil based-drilling 
fluids.

\section{CONCLUSION}

Based on the results and discussions above, several conclusions can be drawn.

511 Organic surfactants occupy the surface and interlayer space of Mnt by electrostatic attraction. Interaction happens between the Mnt layers and polar heads of surfactants only. Interaction between organic cations has a critical influence on the stability of

514 OMnt in oil. The style of arrangement of a surfactant with a single long alkyl chain changed from a pseudo-trimolecular layer to a paraffin-tape bilayer with the increase of the surfactant's loading level. Surfactants with two long alkyl chains arranged as a

517 paraffin-type. Paraffin-type arrangements were more ordered than 518 pseudo-trimolecular layers. A paraffin-type bilayer arrangement of DC18 resulted in 519 more ordered layer stacking than the same arrangement of C18. Tight paraffin-type 520 bilayer arrangements generally led to excellent rheological properties and thermal 521 stability. Loose paraffin-type, pseudo-trimolecular layer and tilted bilayer 522 arrangements resulted in easy dissolution of interlayer organic cations into oil at high 523 temperature. A tight paraffin-type bilayer arrangement of DC18 led to exfoliation of 524 OMnt in oil at high temperatures, improving rheological properties. Organic cations 525 can remain stable in the interlayer space or even on the exfoliated Mnt layers because 526 of the strong interaction force among cations, in addition to the electrostatic attraction. 527 In conclusion, to improve the rheological properties and thermal stability of OMnt in 528 oil-based drilling fluids, more than 1.0 CEC surfactants with two or three long alkyl 
chains are advised.

Acknowledgments

This work was supported financially by the Fundamental Research Funds for

Central Universities (China). The support provided by the China Scholarship Council

(CSC) during the visit of Guanzheng Zhuang (No. 201706400010) to Sorbonne Université is acknowledged.

\section{REFERENCES}

Bergaya, F., Jaber, M., and Lambert, J.F. (2012) Clays and clay minerals as layered nanofillers for (bio)polymers. Pp. 41-75. Springer London.

540

Bertuoli, P.T., Piazza, D., Scienza, L.C., and Zattera, A.J. (2014) Preparation and characterization of montmorillonite modified with 3-aminopropyltriethoxysilane. Applied Clay Science, 87, 46-51.

Bowen, J. P., Pathiaseril, A., Profeta Jr, S., and Allinger, N. L. (1987) New molecular mechanics (MM2) parameters for ketones and aldehydes. The Journal of Organic Chemistry, 52(23), 5162-5166.

Brigatti, M.F., Galan, E., and Theng, B.K.G. (2013) Chapter 2 structures and mineralogy of clay minerals. Pp. 21-81. In F. Bergaya, and G. Lagaly, Eds. Developments in clay science, 5,Elsvier, Netherland.

Caenn, R. and Chillingar, G.V. (1996) Drilling fluids: State of the art. Journal of Petroleum Science and Engineering, 14, 221-230. 
Caenn, R., Darley, H.C., and Gray, G.R. (2011) Composition and properties of drilling and completion fluids. Gulf professional publishing, Houston.

Chen, D., Zhu, J.X., Yuan, P., and Yang, S.J. (2008) Preparation and characterization of anion-cation surfactants modified montmorillonite. Journal of Thermal Analysis and Calorimetry, 94, 841-848.

Dino, D. and Thompson, J. (2002). U.S. Patent No. 6,462,096. Washington, DC: U.S. Patent and Trademark Office.

Favre, H. and Lagaly, G. (1991) Organo-bentonites with quaternary alkylammonium ions. Clay Minerals, 26, 19-32.

Frantz, E. B. (2014). U.S. Patent No. 0,011,712. Washington, DC: U.S. Patent and Trademark Office.

Greene-Kelly R. (1957) The montmorillonite minerals. In: Mackenzie RC, Editor. The differential thermal investigation of clays. London: Mineral Society, p 140-164.

Guégan, R., Giovanela, M., Warmont, F., and Motelica-Heino, M. (2015) Nonionic organoclay: A 'swiss army knife' for the adsorption of organic micro-pollutants? Journal of Colloid and Interface Science, 437, 71-79.

Gunawan, N.S., Indraswati, N., Ju, Y.H., Soetaredjo, F.E., Ayucitra, A., and Ismadji, S. (2010) Bentonites modified with anionic and cationic surfactants for bleaching of crude palm oil. Applied Clay Science, 47, 462-464.

He, H., Ding, Z., Zhu, J., Yuan, P., Xi, Y., Yang, D., and Frost, R.L. (2005) Thermal characterization of surfactant-modified montmorillonites. Clays and Clay 
He, H., Ma, Y., Zhu, J., Yuan, P., and Qing, Y. (2010) Organoclays prepared from montmorillonites with different cation exchange capacity and surfactant configuration. Applied Clay Science, 48, 67-72.

He, H., Zhou, Q., Frost, R.L., Wood, B.J., Duong, L.V., and Kloprogge, J.T. (2007) A x-ray photoelectron spectroscopy study of hdtmab distribution within organoclays. Spectrochimica Acta Part A Molecular and Biomolecular Spectroscopy, 66, 1180-1188.

Hedley, C.B., Yuan, G., and Theng, B.K.G. (2007) Thermal analysis of montmorillonites modified with quaternary phosphonium and ammonium surfactants. Applied Clay Science, 35, 180-188.

Hermoso, J., Martinez-Boza, F., and Gallegos, C. (2014) Influence of viscosity modifier nature and concentration on the viscous flow behavior of oil-based drilling fluids at high pressure. Applied Clay Science, 87, 14-21.

Hermoso, J., Martinez-Boza, F., and Gallegos, C. (2015) Influence of aqueous phase volume fraction, organoclay concentration and pressure on invert-emulsion oil muds rheology. Journal of Industrial and Engineering Chemistry, 22, 341-349.

Hermoso, J., Martínez-Boza, F. J., and Gallegos, C. (2017). Organoclay influence on high pressure-high temperature volumetric properties of oil-based drilling fluids. Journal of Petroleum Science and Engineering, 151, 13-23.

Jaber, M., Georgelin, T., Bazzi, H., Costatorro, F., and Clodic, G. (2014) Selectivities in adsorption and peptidic condensation in the (arginine and glutamic 

25447-25455.

597

598

599

600

601

602

603

604

605

606

607

608

609

610

611

612

613

614

615

616

Jaber, M., Miehe-Brendle, J., and Dred, R.L. (2002) Mercaptopropyl al-mg phyllosilicate: Synthesis and characterization by xrd, ir, and nmr. Chemistry Letters, 80, 954-955.

Khodja, M., Canselier, J.P., Bergaya, F., Fourar, K., Khodja, M., Cohaut, N., and Benmounah, A. (2010) Shale problems and water-based drilling fluid optimisation in the hassi messaoud algerian oil field. Applied Clay Science, 49, 383-393.

Kogure, T. (2013) Chapter 2.9 - electron microscopy. Pp. 275-317. In F. Bergaya, and G. Lagaly, Eds. Developments in clay scinence, 5,Elsevier, Netherlands.

Lagaly, G. (1976) Kink-block and gauche-block structures of bimolecular films. Angewandte Chemie International Edition, 15, 575-586.

Lagaly, G. (1981) Characterization of clays by organic compounds. Clay minerals, 16(1), 1-21.

Lagaly, G. (1986) Interaction of alkylamines with different types of layered compounds. Solid State Ionics, 22, 43-51.

Lagaly, G., Ogawa, M., and Dékány, I. (2013) Chapter 10.3 clay mineral-organic interactions. Pp. 435-505. In F. Bergaya, G.B.K. Theng, and G. Lagaly, Eds. Developments in clay science, 5,Elsevier.

Lee, S.M. and Tiwari, D. (2012) Organo and inorgano-organo-modified clays in the remediation of aqueous solutions: An overview. Applied Clay Science, s 59-60, 
618 Paiva, L.B.D., Morales, A.R., and Díaz, F.R.V. (2008) Organoclays: Properties, preparation and applications. Applied Clay Science, 42, 8-24.

620

621

622

623

624

625

626

627

628

629

630

631

632

633

634

635

636

637

638

Ratkievicius, L. A., Da Cunha Filho, F. J. V., Neto, E. L. D. B., Santanna, V. C. (2017). Modification of bentonite clay by a cationic surfactant to be used as a viscosity enhancer in vegetable-oil-based drilling fluid. Applied Clay Science, 135, 307-312.

Sarier, N., Onder, E., and Ersoy, S. (2010) The modification of na-montmorillonite by salts of fatty acids: An easy intercalation process. Colloids and Surfaces A Physicochemical and Engineering Aspects, 371, 40-49.

Schampera, Solc, B., Woche, R., Mikutta, S.K., Dultz, R., Guggenberger, S., Tunega, G., and D. (2015) Surface structure of organoclays as examined by x-ray photoelectron spectroscopy and molecular dynamics simulations. Clay Minerals, 50, 353-367.

Shen, Y. H. (2001) Preparations of organobentonite using nonionic surfactants. Chemosphere, 44, 989-995.

Vaia, R.A., Teukolsky, R. K., and Giannelis, E.P. (1994) Interlayer structure and molecular environment of alkylammonium layered silicates. Chemistry of Materials, 6, 1017-1022.

Wu, S., Zhang, Z., Wang, Y., Liao, L., and Zhang, J. (2014) Influence of montmorillonites exchange capacity on the basal spacing of cation-anion organo-montmorillonites. Materials Research Bulletin, 59, 59-64. 
639

640

641

642

643

644

645

646

647

648

649

650

651

652

653

654

655

656

657

658

659

660

Zhang, Z., Liao, L., and Xia, Z. (2010) Ultrasound-assisted preparation and characterization of anionic surfactant modified montmorillonites. Applied Clay Science, 50, 576-581.

Zhang, Z., Zhang, J., Liao, L., and Xia, Z. (2013) Synergistic effect of cationic and anionic surfactants for the modification of ca-montmorillonite. Materials Research Bulletin, 48, 1811-1816.

Zhu, J., Qing, Y., Wang, T., Zhu, R., Wei, J., Tao, Q., Yuan, P., and He, H. (2011) Preparation and characterization of zwitterionic surfactant-modified montmorillonites. Journal of Colloid and Interface Science, 360, 386-392.

Zhuang, G., Gao, J., Chen, H., and Zhang, Z. (2018) A new one-step method for physical purification and organic modification of sepiolite. Applied Clay Science, 153, 1-8.

Zhuang, G., Zhang, H., Wu, H., Zhang, Z., and Liao, L. (2017a) Influence of the surfactants' nature on the structure and rheology of organo-montmorillonite in oil-based drilling fluids. Applied Clay Science, 135, 244-252.

Zhuang, G., Zhang, Z., Gao, J., Zhang, X., and Liao, L. (2017b) Influences of surfactants on the structures and properties of organo-palygorskite in oil-based drilling fluids. Microporous and Mesoporous Materials, 244, 37-46.

Zhuang, G., Zhang, Z., Guo, J., Liao, L., and Zhao, J. (2015) A new ball milling method to produce organo-montmorillonite from anionic and nonionic surfactants. Applied Clay Science, 104, 18-26.

Zhuang, G., Zhang, Z., Jaber, M., Gao, J., and Peng, S. (2017c) Comparative study on 
the structures and properties of organo-montmorillonite and organo-palygorskite in oil-based drilling fluids. Journal of Industrial and Engineering Chemistry, 56, 248-257.

Zhuang, G., Zhang, Z., Sun, J., and Liao, L. (2016) The structure and rheology of organo-montmorillonite in oil-based system aged under different temperatures. Applied Clay Science, 124, 21-30.

\section{FIGURE CAPTIONS:}

Figure 1. XRD pattern of Mnt with the JCPDS cards of montmorillonite, quartz, calcite, albite, and pyrite.

Figure 2. Structural diagrams of organic cations with optimized geometrical shapes and molecular sizes.

Figure 3. XRD patterns of OMnt samples.

Figure 4. TEM images of Mnt and OMnt samples.

Figure 5. TG and corresponding DTG curves of Mnt, organic surfactants, and OMnt samples.

Figure 6. XPS survey scans of Mnt and OMnt samples.

Figure 7. O 1s high-resolution XPS spectra of Mnt and OMnt samples.

Figure 8. Si 2p high-resolution XPS spectra of Mnt and OMnt samples.

Figure 9. Al 2p high-resolution XPS spectra of Mnt and OMnt samples.

Figure 10. C 1s high-resolution XPS spectra of surfactants and OMnt samples.

Figure 11. N 1s high-resolution XPS spectra of surfactants and OMnt samples. 
683 Figure 12. Schematic diagram of the different arrangements of surfactants in the 684 interlayer space of OMnt.

685 Figure 13. Dynamic rheological curves of OMnt/oil fluids aged at $66^{\circ} \mathrm{C}, 150^{\circ} \mathrm{C}$, $686180^{\circ} \mathrm{C}$, and $200^{\circ} \mathrm{C}$.

687 Figure 14 . XRD results for OMnt/oil gels aged at $66^{\circ} \mathrm{C}, 150^{\circ} \mathrm{C}, 180^{\circ} \mathrm{C}$, and $200^{\circ} \mathrm{C}$.

688 Tables:

689

690 Table 1. K-values of selected minerals.

\begin{tabular}{lllll}
\hline Mineral & $(h k l)$ & ${ }^{\circ} 2 \theta$ & $d$ value $(\mathrm{nm})$ & K-value \\
\hline Corundum & $(104)$ & 35.16 & 0.2550 & 1.00 \\
Montmorillonite & $(020)$ & 19.80 & 0.4880 & 0.50 \\
Quartz & $(101)$ & 26.65 & 0.3343 & 4.32 \\
Calcite & $(104)$ & 29.42 & 0.3034 & 2.80 \\
Albite & $(002)$ & 27.92 & 0.3193 & 1.80 \\
Pyrite & $(200)$ & 33.00 & 0.2712 & 2.06 \\
\hline
\end{tabular}

691

692

693 Table 2. A summary of the components in the Mnt sample.

\begin{tabular}{llllll}
\hline Component & Montmorillonite & Quartz & Calcite & Albite & Pyrite \\
\hline Mass $(\%)$ & $88 \%$ & $7 \%$ & $2 \%$ & $2 \%$ & $1 \%$ \\
\hline
\end{tabular}


Table 3. Summary of basal spacings derived from XRD and TEM.

\begin{tabular}{llll}
\hline Sample & $d_{001}(\mathrm{XRD}) / \mathrm{nm}$ & $d_{001}(\mathrm{TEM}) / \mathrm{nm}$ & $\Delta d_{001} / \mathrm{nm}$ \\
\hline C18-Mnt-1.0 & 2.12 & $1.44-1.79$ & $0.33-0.68$ \\
C18-Mnt-2.0 & 4.06 & 1.87 & 2.19 \\
DC18-Mnt-0.5 & 3.51 & 2.42 & 1.09 \\
DC18-Mnt-1.0 & 3.68 & 2.53 & 1.15 \\
\hline
\end{tabular}

$697 \quad$ Note: $\Delta d_{001}=d_{001}(\mathrm{XRD})-d_{001}(\mathrm{TEM})$

698

699 Table 4. Summary of $\triangle B E$ values.

\begin{tabular}{llll}
\hline \multirow{2}{*}{ Sample } & \multicolumn{1}{c}{$\Delta \mathrm{BE}(\mathrm{eV})$} & \\
\cline { 2 - 4 } & $\mathrm{O} 1 \mathrm{~s}$ & $\mathrm{C} 1 \mathrm{~s}(\mathrm{C}-\mathrm{N})$ & $\mathrm{N} 1 \mathrm{~s}$ \\
\hline C18-Mnt-1.0 & -1.2 & 0.5 & 0.3 \\
C18-Mnt-2.0 & -1.0 & 0.4 & 0.3 \\
DC18-Mnt-0.5 & -1.1 & 0.5 & 0.2 \\
DC18-Mnt-1.0 & -1.2 & 0.3 & 0.1 \\
\hline
\end{tabular}

Note: $\Delta \mathrm{BE}(\mathrm{O} 1 \mathrm{~s})=\mathrm{BE}(\mathrm{O} 1 \mathrm{~s}, \mathrm{OMnt})-\mathrm{BE}(\mathrm{O} 1 \mathrm{~s}, \mathrm{Mnt}) ; \Delta \mathrm{BE}(\mathrm{C} 1 \mathrm{~s})=\mathrm{BE}(\mathrm{C} 1 \mathrm{~s}$,

701 OMnt $)-\mathrm{BE}(\mathrm{C} 1 \mathrm{~s}$, surfactant $)$; and $\triangle \mathrm{BE}(\mathrm{N} 1 \mathrm{~s})=\mathrm{BE}(\mathrm{N} 1 \mathrm{~s}$, OMnt $)-\mathrm{BE}(\mathrm{N} 1 \mathrm{~s}$, 702 surfactant).

703

704 Table 5. Rheological properties of OMnt/oil fluids aged at different temperatures.

\begin{tabular}{llll}
\hline Sample & AV (mPa.s $)$ & PV (mPa.s $)$ & YP $(\mathrm{Pa})$ \\
\cline { 2 - 3 } & &
\end{tabular}




\begin{tabular}{|c|c|c|c|c|c|c|c|c|c|c|c|c|}
\hline & $66^{\circ} \mathrm{C}$ & $150^{\circ} \mathrm{C}$ & $180^{\circ} \mathrm{C}$ & $200^{\circ} \mathrm{C}$ & $66^{\circ} \mathrm{C}$ & $150^{\circ} \mathrm{C}$ & $180^{\circ} \mathrm{C}$ & $200^{\circ} \mathrm{C}$ & $66^{\circ} \mathrm{C}$ & $150^{\circ} \mathrm{C}$ & $180^{\circ} \mathrm{C}$ & $200^{\circ} \mathrm{C}$ \\
\hline DG-Mnt & 16.0 & 17.0 & 15.5 & 15.0 & 16.0 & 16.0 & 15.0 & 15.0 & 0.0 & 1.0 & 0.5 & 0.0 \\
\hline C18-Mnt-1.0/oil & 14.5 & 15.0 & 15.0 & 14.0 & 14.5 & 14.5 & 14.5 & 14.0 & 0.0 & 0.5 & 0.5 & 0.0 \\
\hline C18-Mnt-2.0/oil & 16.5 & 31.0 & 26.5 & 24.0 & 16.0 & 16.0 & 21.0 & 21.0 & 0.5 & 15.0 & 5.5 & 3.0 \\
\hline DC18-Mnt-0.5/oil & 15.0 & 15.0 & 16.0 & 15.0 & 15.0 & 14.5 & 16.0 & 14.5 & 0.0 & 0.5 & 0.0 & 0.5 \\
\hline DC18-Mnt-1.0/oil & 24.5 & 47.0 & 43.0 & 40.0 & 21.0 & 29.0 & 26.0 & 25.0 & 3.5 & 18.0 & 17.0 & 15.0 \\
\hline
\end{tabular}

705

706

707 Table 6. Areas of thixotropic loops derived from Figure 13.

\begin{tabular}{lllll}
\hline \multirow{2}{*}{ Sample } & \multicolumn{4}{l}{ Areas of thixotropic loops $\left(\mathrm{Pa} \cdot \mathrm{s}^{-1}\right)$} \\
\cline { 2 - 5 } & $66^{\circ} \mathrm{C}$ & $150^{\circ} \mathrm{C}$ & $180^{\circ} \mathrm{C}$ & $200^{\circ} \mathrm{C}$ \\
\hline DG-Mnt/oil & 4.25 & 3.65 & 3.07 & 4.45 \\
C18-Mnt-1.0/oil & 1.62 & 1.64 & 1.52 & 1.45 \\
C18-Mnt-2.0/oil & 2.61 & 193.43 & 75.50 & 27.50 \\
DC18-Mnt-0.5/oil & 3.40 & 3.84 & 1.65 & 1.43 \\
DC18-Mnt-1.0/oil & 26.21 & 424.68 & 394.94 & 342.85 \\
\hline
\end{tabular}

708

709

710 FIGURES:

711 


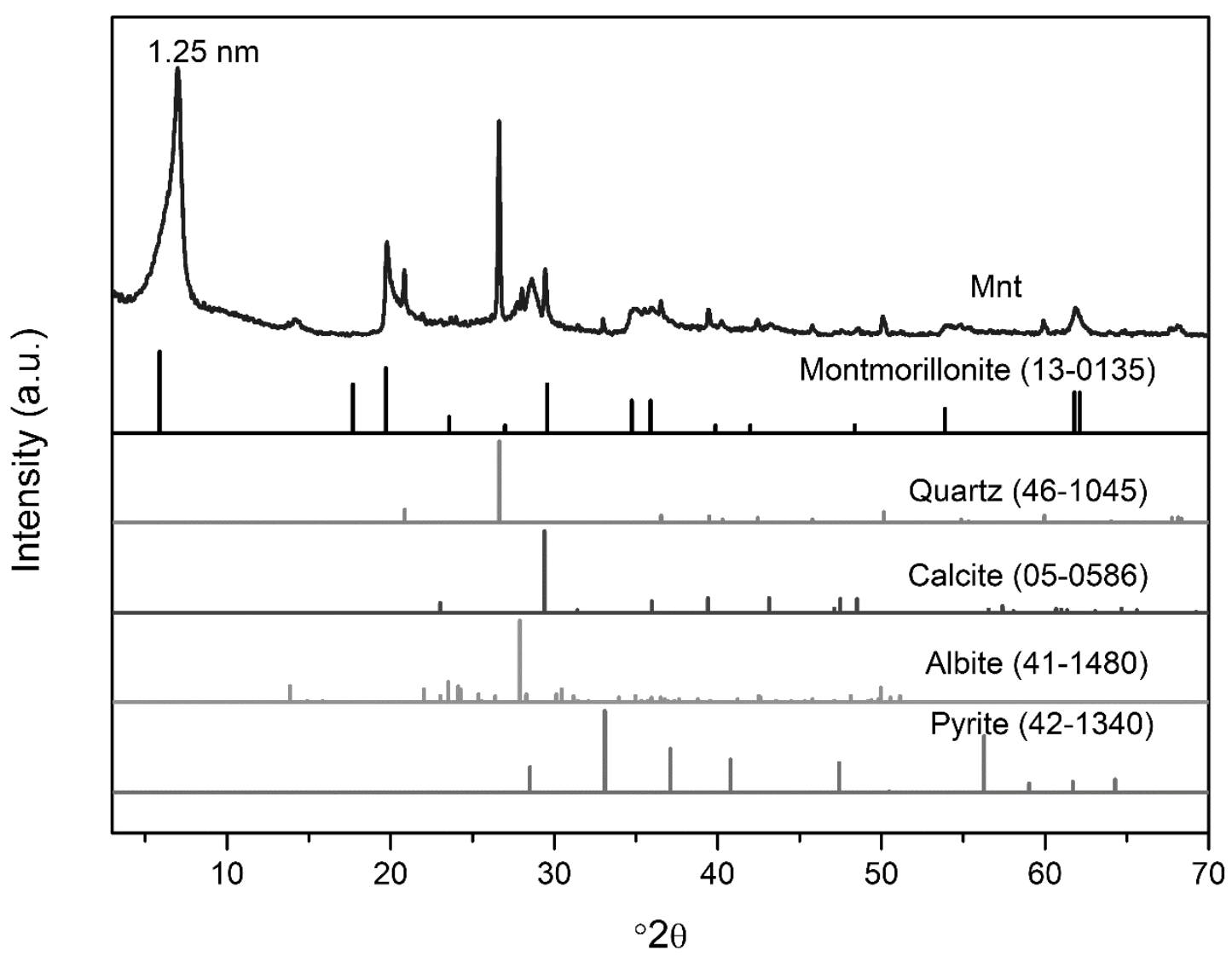

713 Figure 1 XRD pattern of Mnt with the JCPDS cards of montmorillonite, quartz, 714 calcite, albite and pyrite. 


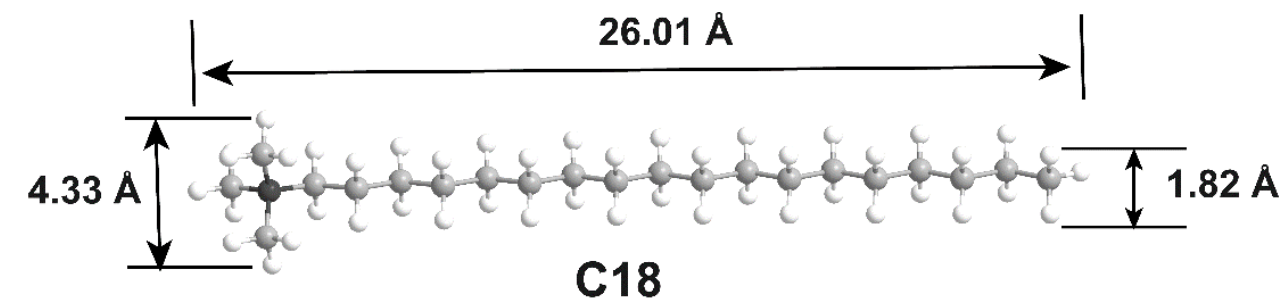

716

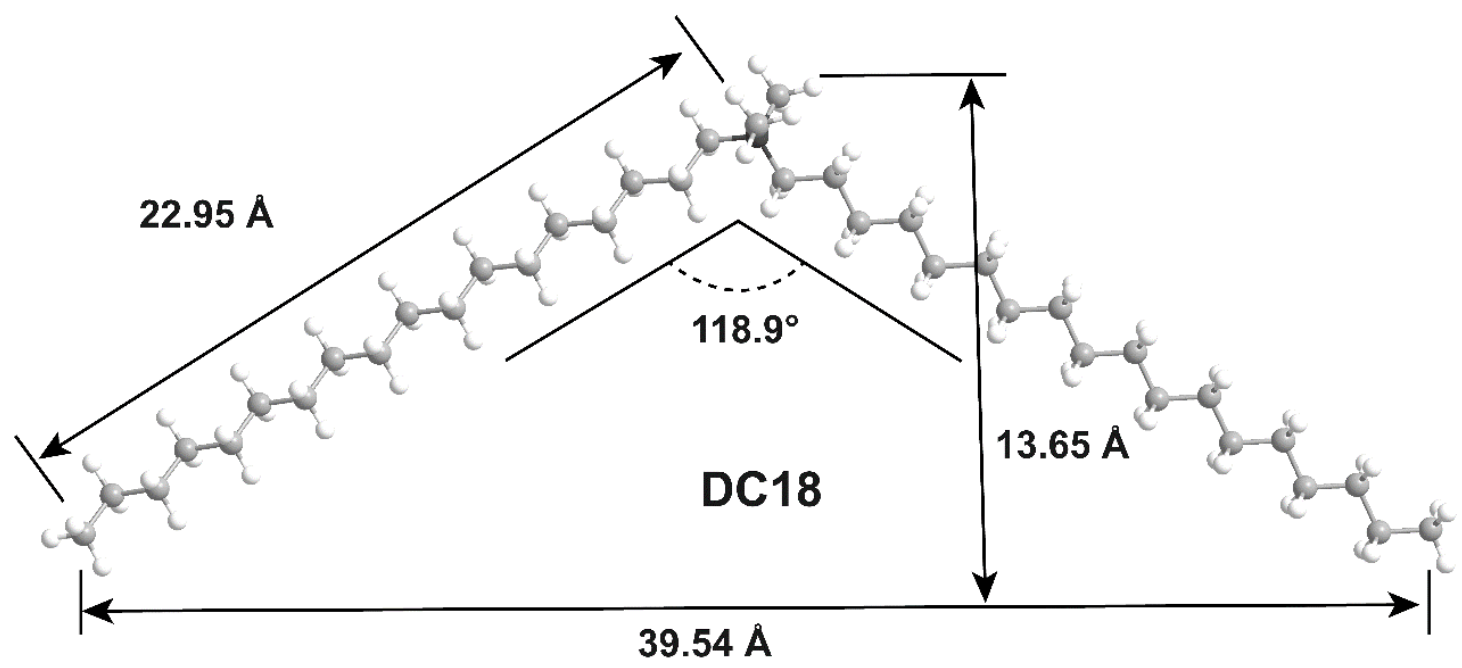

717 Figure 2 Structural diagrams of organic cations with the optimized geometrical shapes 718 and molecular sizes. 

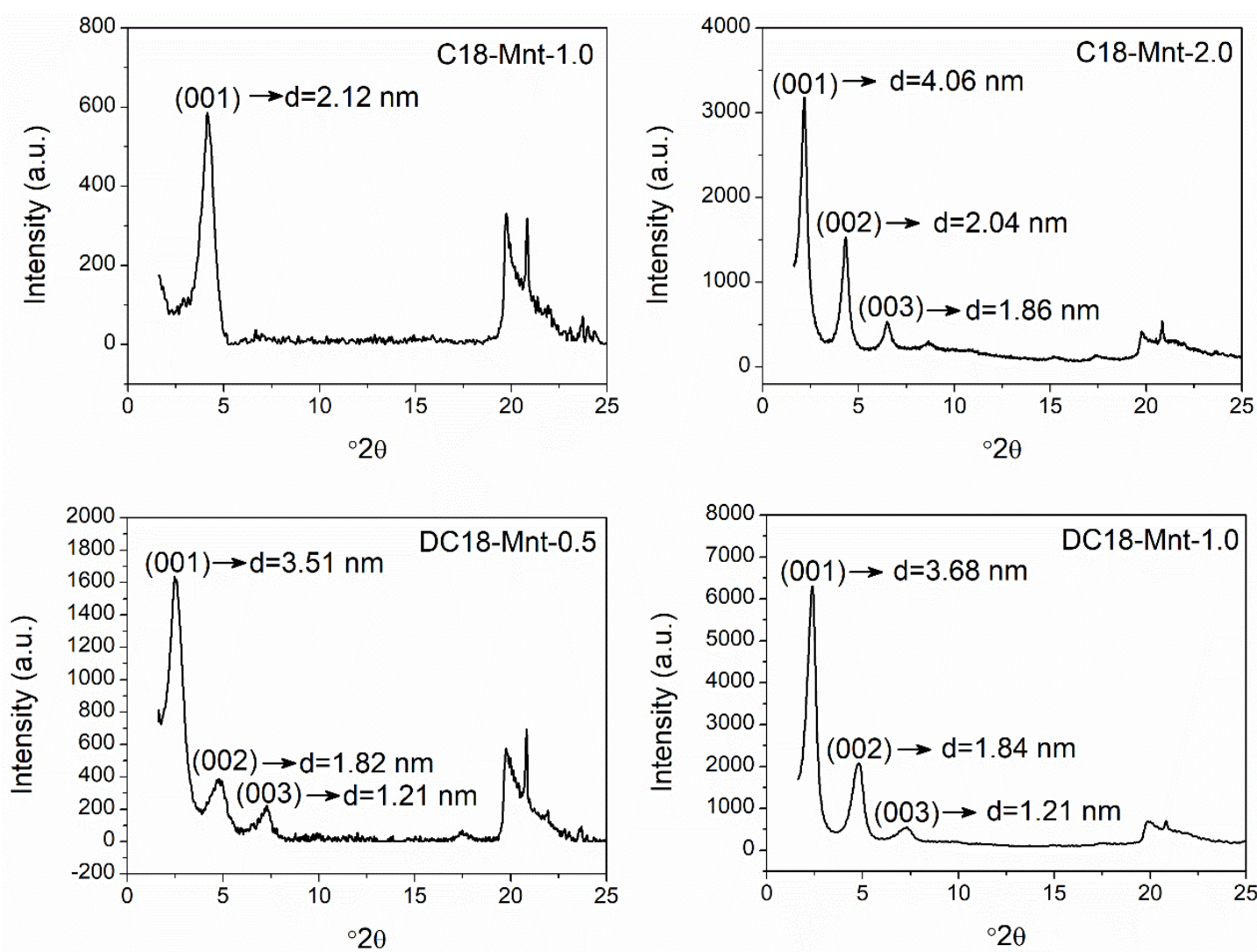

720

721 Figure 3 XRD patterns and OMnt samples. 

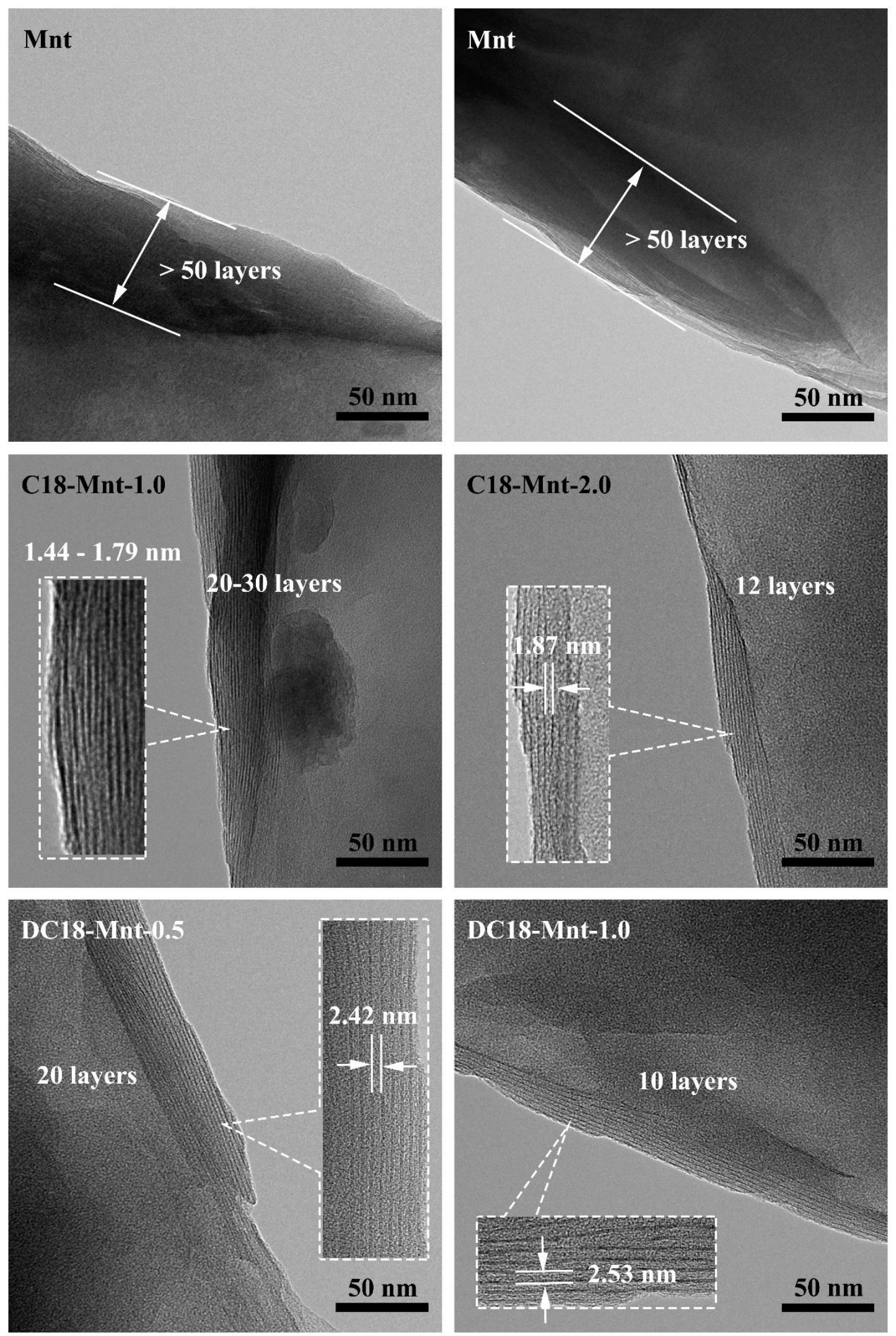

Figure 4 TEM images of Mnt and OMnt samples. 

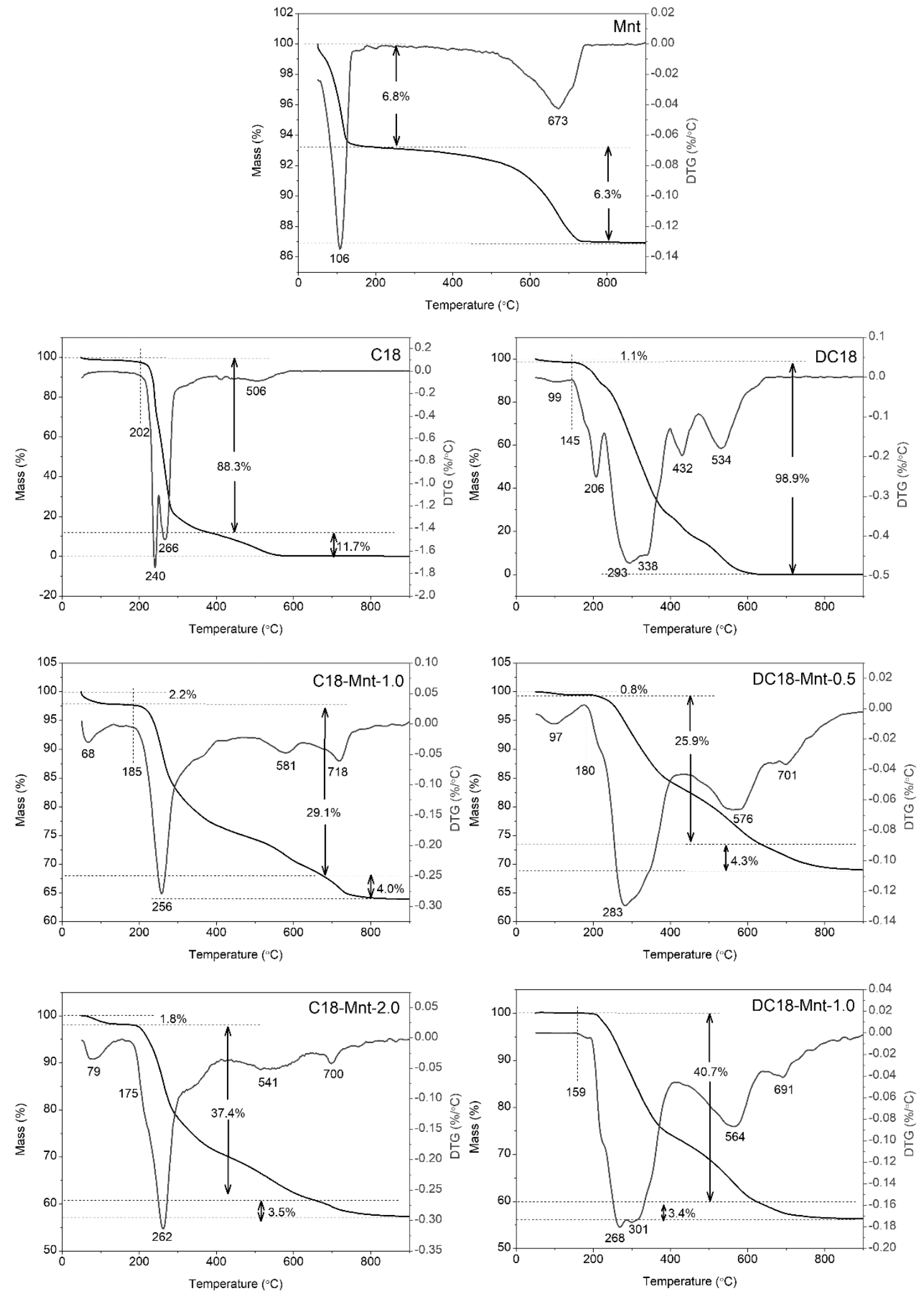

727 Figure 5 The TG and corresponding DTG curves of Mnt, organic surfactants, and

OMnt samples. 


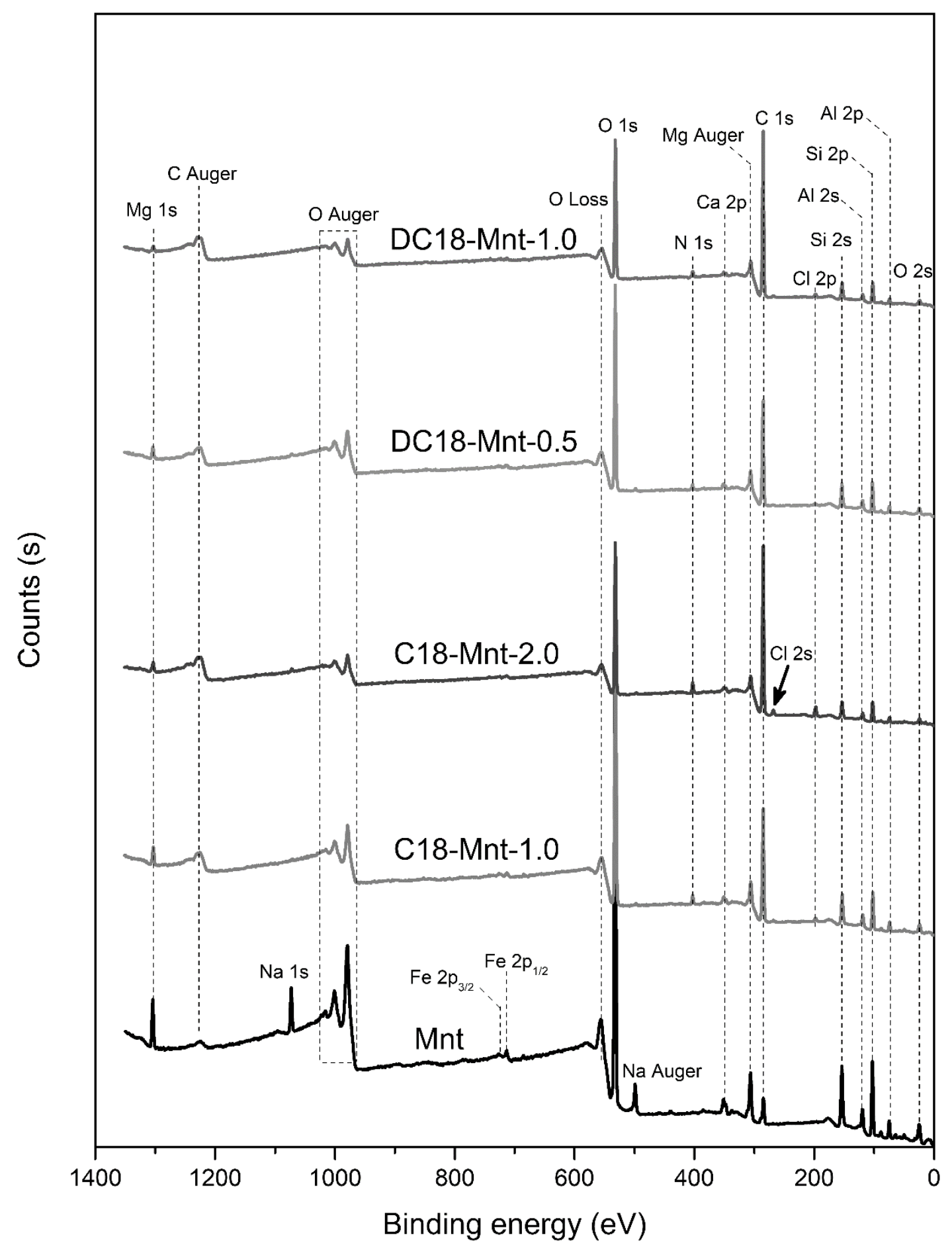

731 Figure 6 Survey scans of Mnt and OMnt samples. 

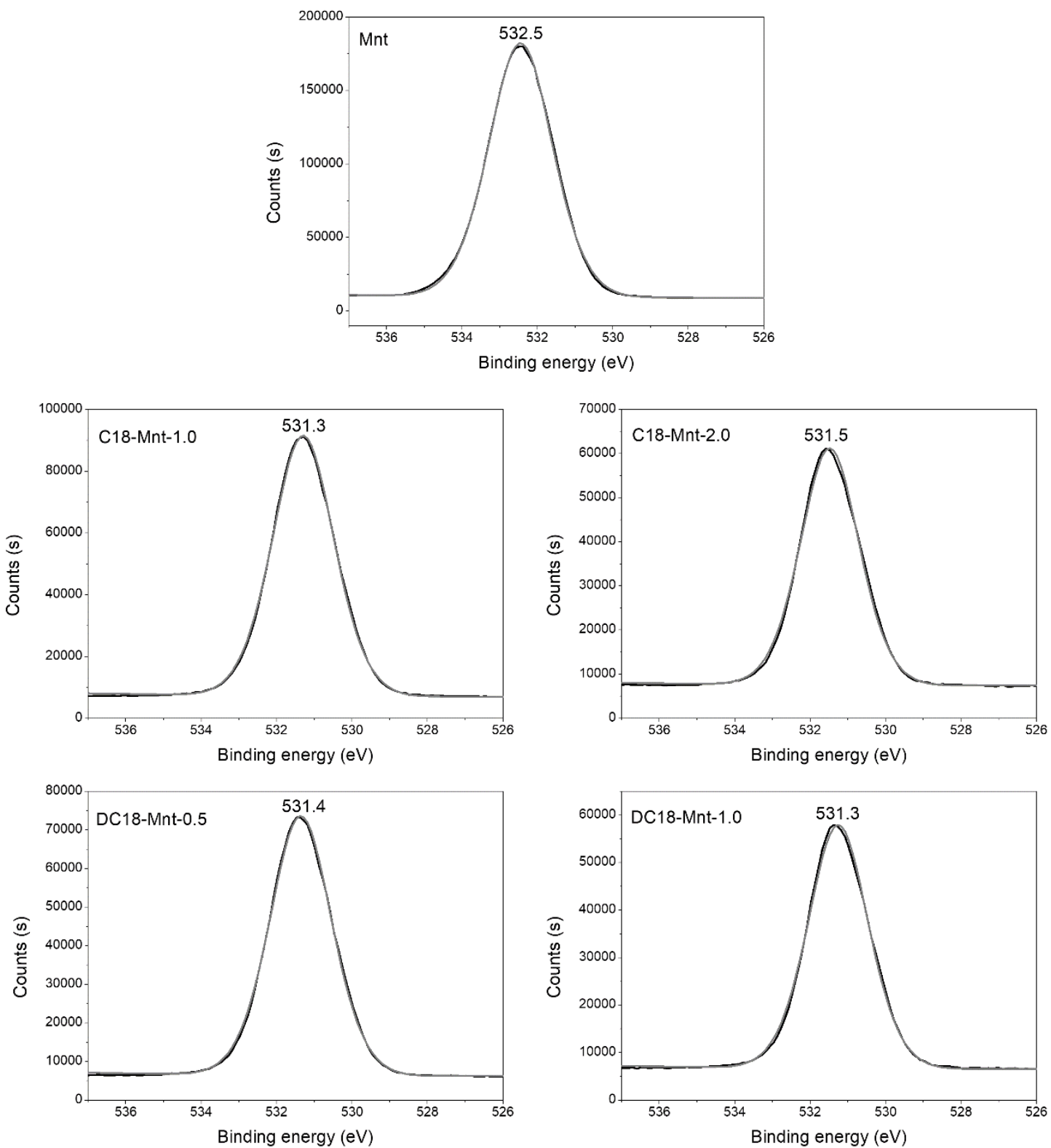

734 Figure $7 \mathrm{O}$ 1s high-resolution XPS spectra of Mnt and OMnt samples. 

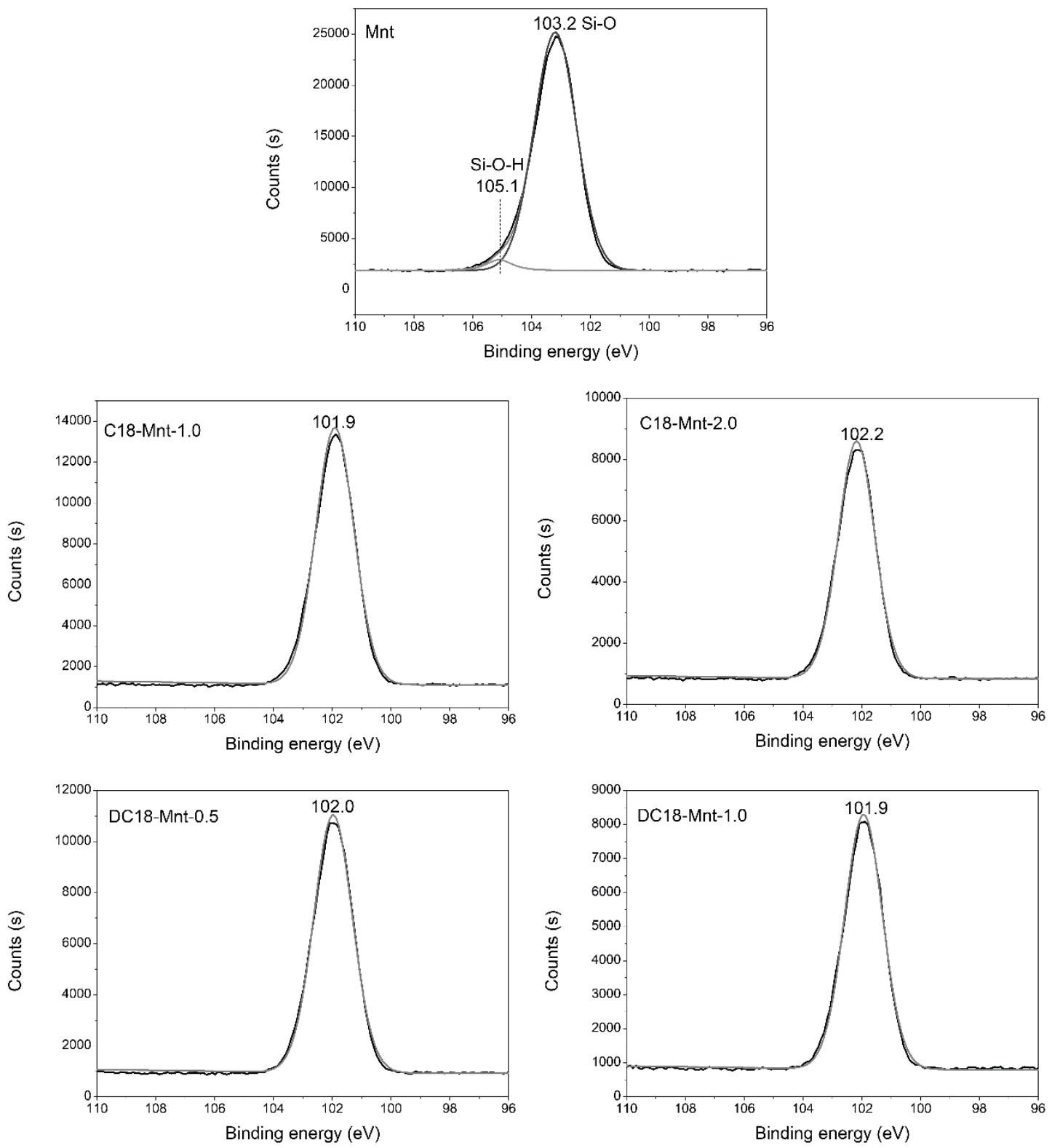

Fig. 8 Si 2p high-resolution XPS spectra of Mnt and OMnt samples.

738 

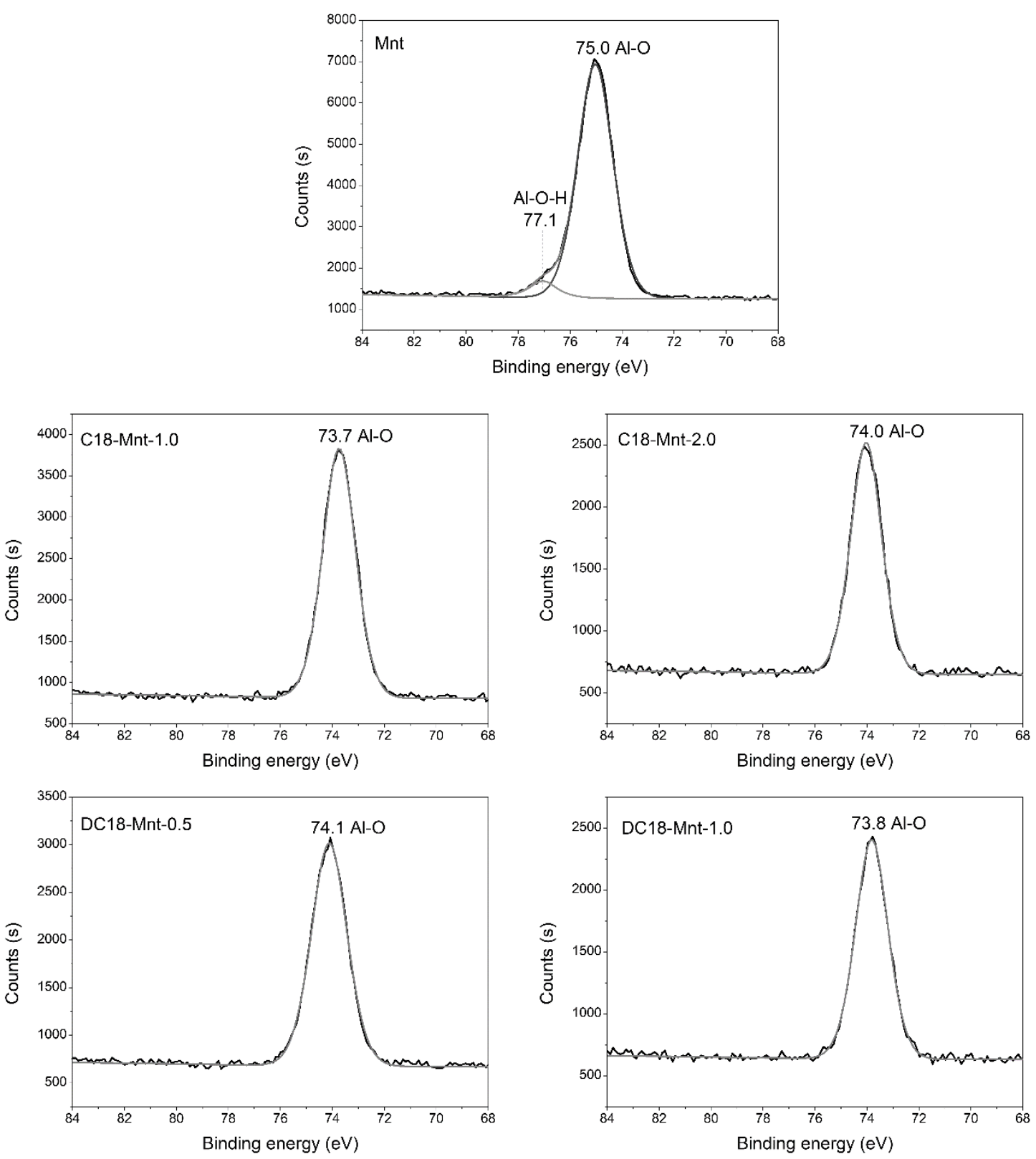

Fig. $9 \mathrm{Al} 2 p$ high-resolution XPS spectra of Mnt and OMnt samples. 

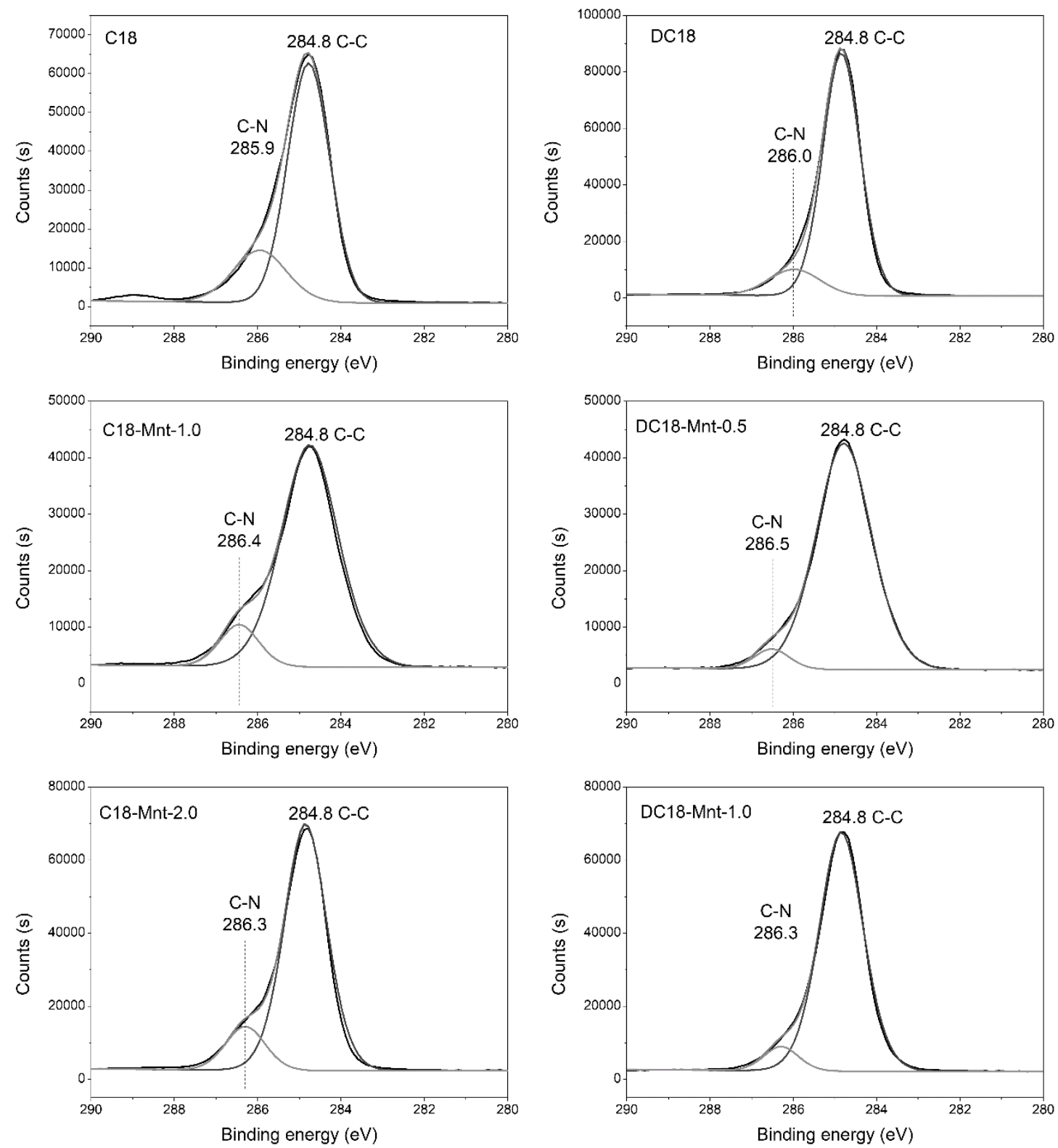

743 Figure $10 \mathrm{C} 1 \mathrm{~s}$ high-resolution XPS spectra of surfactants and OMnt samples. 

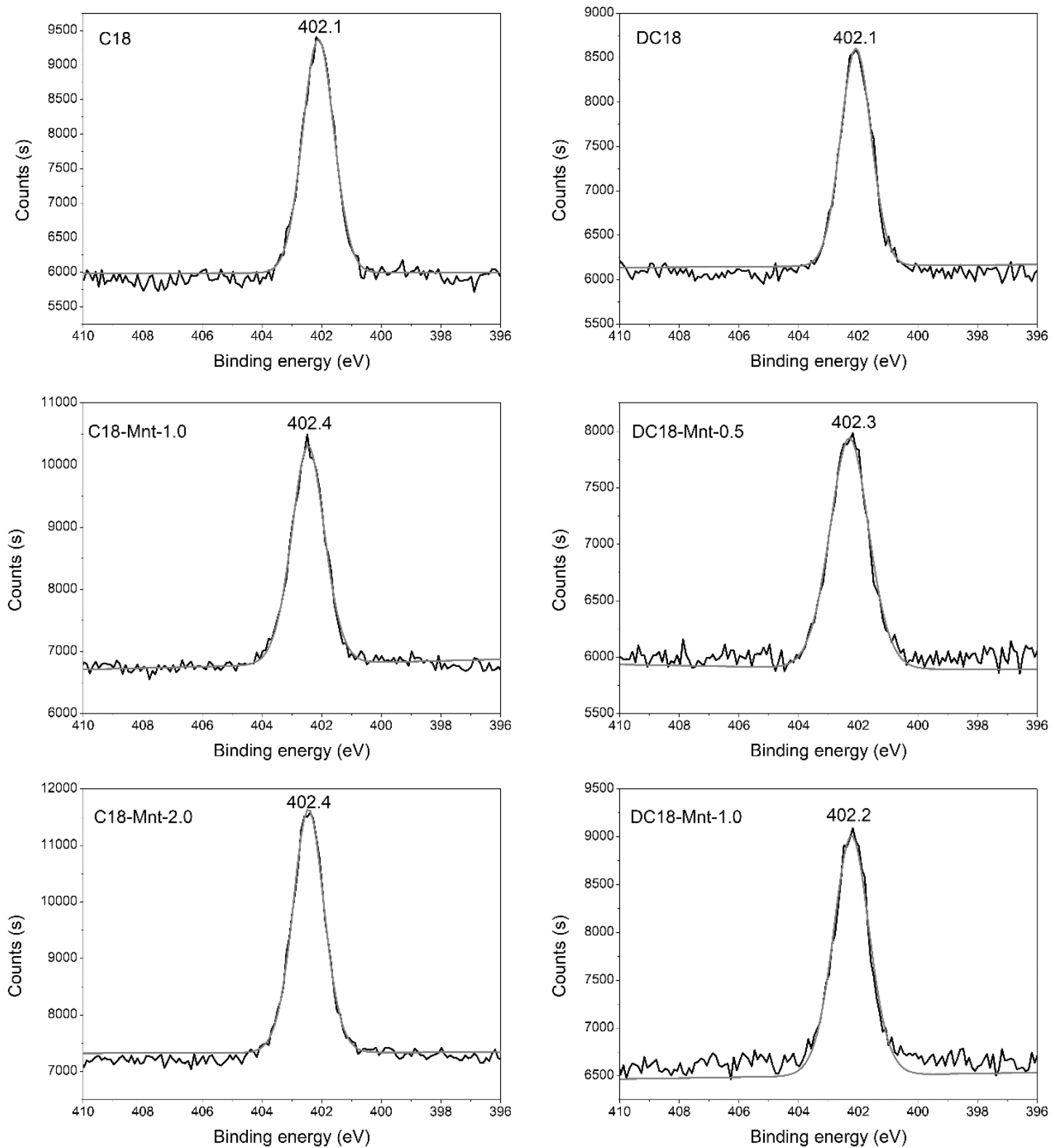

746 Figure $11 \mathrm{~N}$ 1s high-resolution XPS spectra of surfactants and OMnt samples. 

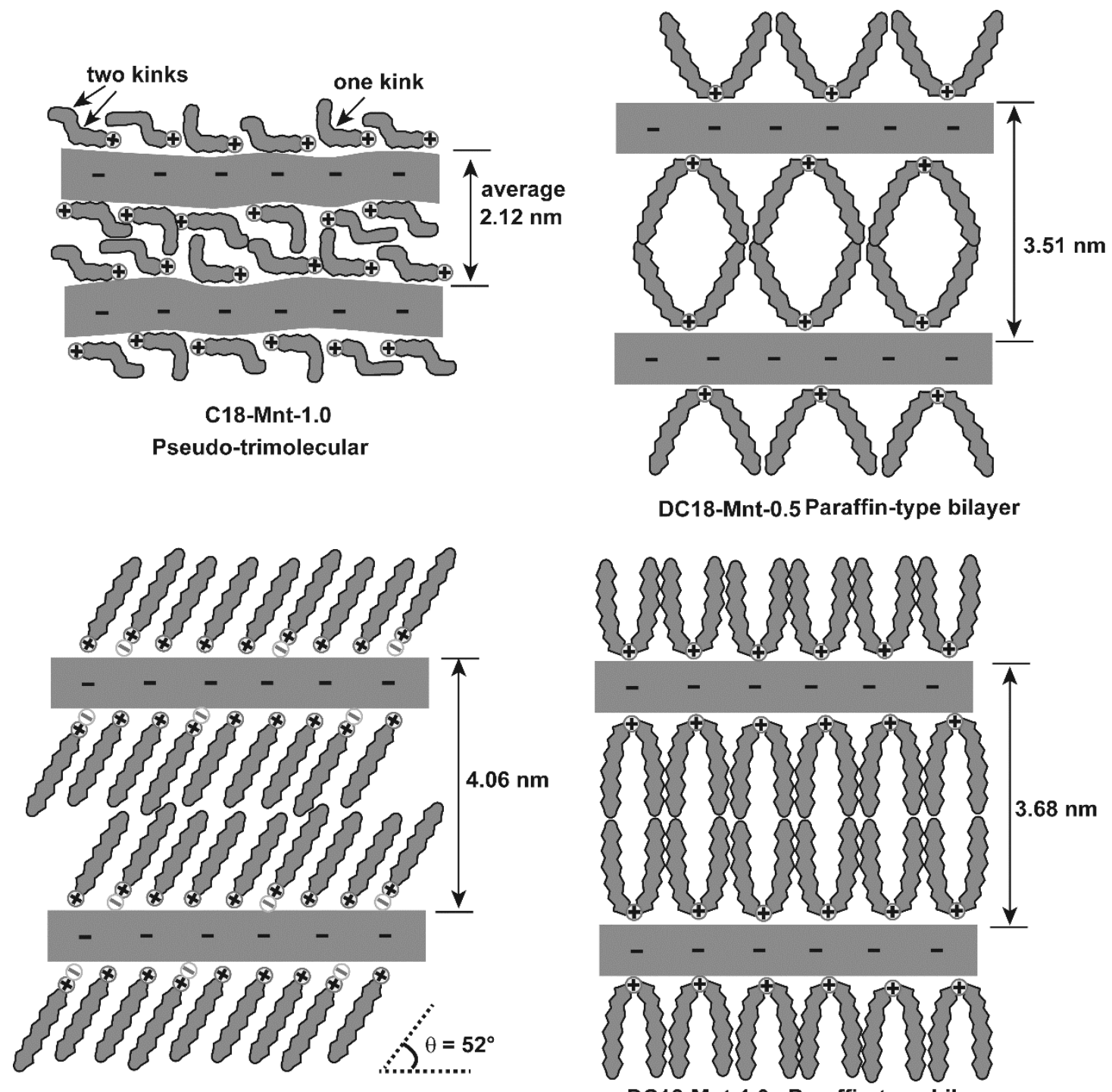

C18-Mnt-2.0 Paraffin-type bilayer

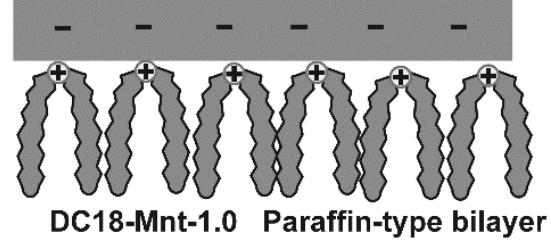

748

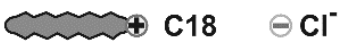
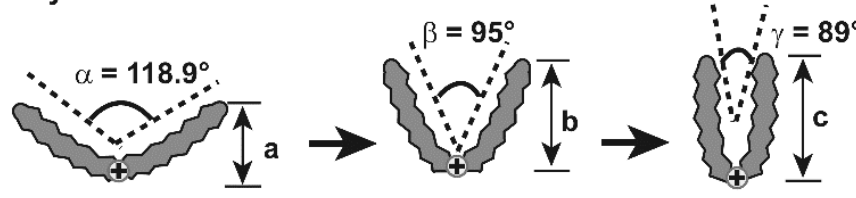

749 Figure 12 Schematically interpretive diagram of arrangements of surfactants in the

750 interlayer space of OMnt. 

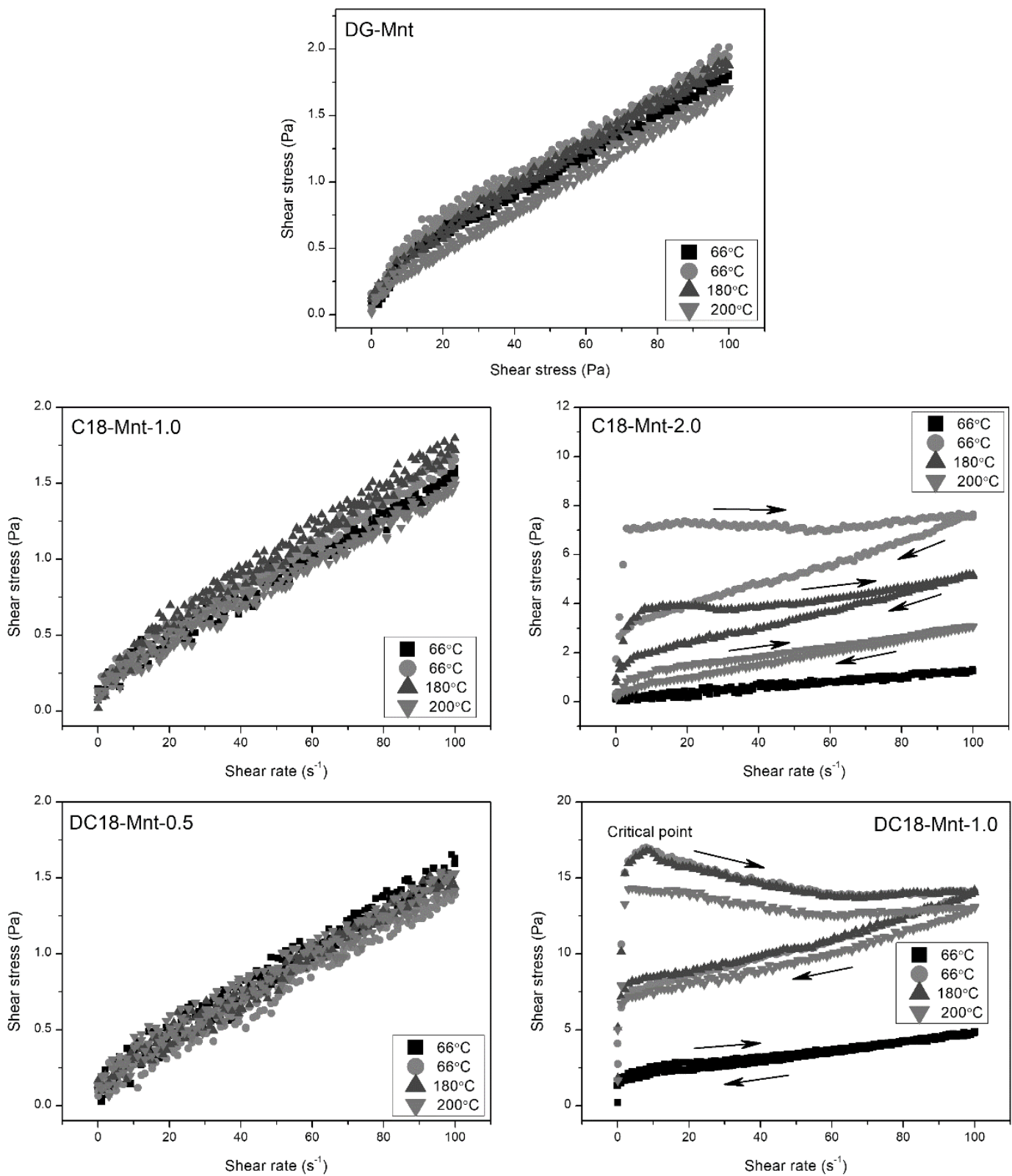

Figure 13 Dynamic rheological curves of OMnt/oil fluids aged at $66^{\circ} \mathrm{C}, 150^{\circ} \mathrm{C}, 180^{\circ} \mathrm{C}$ 754 and $200^{\circ} \mathrm{C}$. 

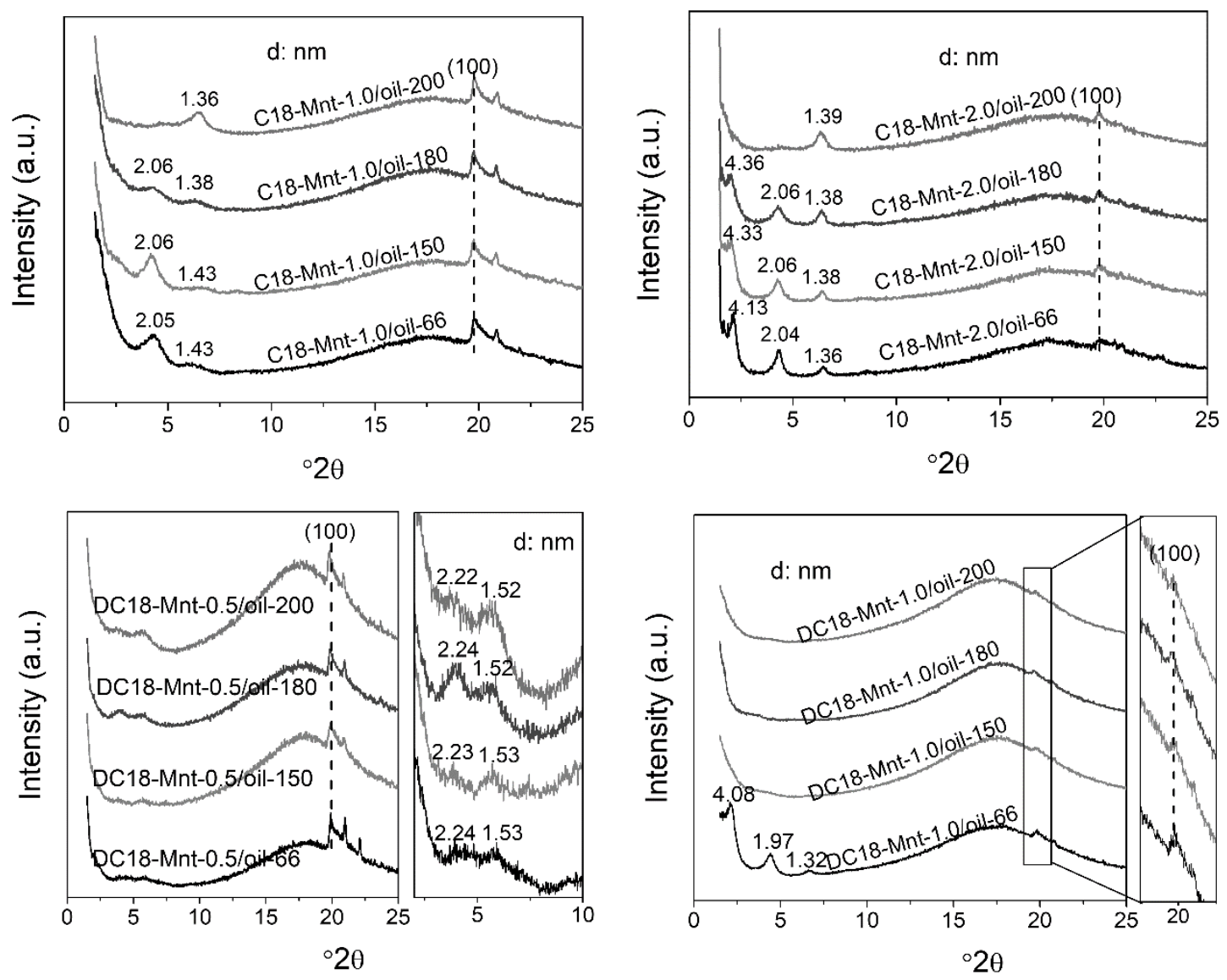

757 Figure $14 \mathrm{XRD}$ results of OMnt/oil gels aged at $66^{\circ} \mathrm{C}, 150^{\circ} \mathrm{C}, 180^{\circ} \mathrm{C}$ and $200^{\circ} \mathrm{C}$. 